\title{
Research of Roof Anchorage Rock Beam Bearing Structure Model of Extra-Large Width Open-Off Cut and Its Engineering Application in a Coal Mine, China
}

\author{
Shengrong Xie $\mathbb{D}^{1,},{ }^{1,2}$ Qing Zhang, ${ }^{3}$ Dongdong Chen $\mathbb{D}^{1},{ }^{1}$ En Wang, ${ }^{1}$ Junchao Zeng, \\ Chunwei Ji, ${ }^{1}$ Xiaoyu Wu, ${ }^{1}$ Zaisheng Jiang, ${ }^{1}$ Feng Chen, ${ }^{4}$ and Shunxing Qiao ${ }^{4}$ \\ ${ }^{1}$ School of Energy and Mining Engineering, China University of Mining \& Technology, Beijing 100083, China \\ ${ }^{2}$ Beijing Key Laboratory for Precise Mining of Intergrown Energy and Resources, China University of Mining \& Technology, \\ Beijing 100083, China \\ ${ }^{3}$ School of Emergency Management and Safety Engineering, China University of Mining \& Technology, Beijing 100083, China \\ ${ }^{4}$ Xingdong Coal Mine, Jizhong Energy Resources Co., Ltd., Xingtai 054000, China
}

Correspondence should be addressed to Dongdong Chen; chendongbcg@163.com

Received 10 November 2019; Revised 12 May 2020; Accepted 4 November 2020; Published 30 November 2020

Academic Editor: Jinyang Xu

Copyright () 2020 Shengrong Xie et al. This is an open access article distributed under the Creative Commons Attribution License, which permits unrestricted use, distribution, and reproduction in any medium, provided the original work is properly cited.

\begin{abstract}
The stability of the extra-large width open-off cut of a longwall panel has been a major concern in underground solid backfill mining. In this study, a numerical model was built with FLAC3D for analyzing the characteristics of the effective prestressed field distribution in the extra-large width open-off cut roof in Xingdong coal mine, China. The numerical results obtained in this study demonstrate that an anchorage rock beam bearing structure (ARBBS) can be formed. Additionally, the ARBBS model was also constructed. The analytical expression of the maximum shear stress (MSS) in the model was obtained under the functions of composite influencing factors. Then, the MSS evolution laws in ARBBS with different thicknesses and spans were investigated using MATLAB software. The stress changes in ARBBS with a span of $15 \mathrm{~m}$ were compared and analyzed under the functions of single and composite influencing factors. The cooperative control principle of the roof ARBBS and two rib anchorage bearing structures was also clarified. Accordingly, a combined support scheme for an $11.5 \mathrm{~m}$-wide open-off cut was proposed. The field applications demonstrated that the scheme successfully controlled the failure and deformation of the surrounding rock, thus contributing to the fast development of the open-off cut and the quick and timely installations of the backfill mining equipment. This validated the results of the ARBBS model. This study is expected to provide helpful references for other extra-large width open-off cut or roadway stability investigations and rock support design under similar engineering and geological conditions.
\end{abstract}

\section{Introduction}

Open-off cut is a type of roadway of a longwall panel, which is regarded as the beginning of coal seam extraction [1]. It plays a key role in underground coal mining because mining equipment such as hydraulic support and shearer can be installed inside the open-off cut. The width of the open-off cut is usually greater than that of the corresponding headentry or tailentry. Unlike the service life of shafts, main roadways [2], headentries, and tailentries, the service life of an open-off cut is only a few months [3].
The conventional mining technology of not filling the mined-out area, for coal deposits buried under farmlands, villages, and railways, has resulted in the significant surface subsidence. In addition, it has also damaged the surface infrastructure and cultivated land resources. However, over the past few years, the backfill mining technology has effectively controlled surface deformation, improved coal resources recovery rate, and ensured stable and sustainable development of coal enterprises towards green mining [4-6]. In China, scholars have developed a fully mechanized coal mining and goaf solid backfilling integration technology 
$[7,8]$, which has been widely applied in the Xingdong mining area, Xinwen mining area, Wanbei mining area, and so forth. This technique suggests the extensive use of large mining equipment, especially hydraulic support [9]. Subsequently, the open-off cut width has been shown to increase and even extend beyond $11 \mathrm{~m}$. Consequently, it can be expected that the large width open-off cut can significantly contribute to the rapid deformation of the surrounding rock, once it is driven. Additionally, it can also result in the concentration of stress, fracturing and yielding of rock, bed separation, and even roof falling in the surrounding rock, especially the roof subjected to a complex loading pattern. However, the heavy yieldable metal support and grouting cannot be widely employed to reinforce the open-off cut with a short-term service life due to the fast and timely support and cost-efficient principle [10]. Hence, the stability control problems of the large width open-off cut or roadway, with an increase in width, have received much attention.

Based on the aforementioned information, many scholars in China and other countries have studied the stability control principles of the surrounding rock of large width (section) open-off cuts or roadways using different research methods [11]. For example, Jia et al. [12] developed the mechanical models of fractures of the large width open-off cut roof for analyzing the mechanical principle of the roof instability and collapse and calculating the roof fracture spans. The research results were found to be very close to the field observation results. He et al. [13] constructed a natural equilibrium arch model of the large width open-off cut surrounding rock failure based on Protojiakonov's theory. It was assumed that the vertical rock pressure rapidly increased and easily resulted in the instability and failure of the two ribs with increasing openoff cut width. Using plastic mechanics, Meng et al. [14] developed an analytical model of the slip-line field for a large section of circular soft rock roadway and derived the shear slip failure limit load and reasonable support resistance for the support scheme design. In addition, Xie et al. [15] applied FLAC3D to analyze the failure mechanism of a large section of chamber under a $1200 \mathrm{~m}$ deep goaf. The simulation results demonstrated that the entire chamber was in the plastic zone and in a relatively high stress environment even after the pressure was relieved. Subsequently, the comprehensive control technology was proposed. Zhang et al. [16] used UDEC to simulate the weakening effect of the fault on the surrounding rock of a large section of roadway along a fault to drivage under strong mining. They subsequently compared and analyzed the vertical stress distribution laws in the rock mass surrounding roadway during the drivage and mining stages under the original and new support schemes, respectively. $\mathrm{Yu}$ and $\mathrm{Du}$ [17] employed FLAC2D to investigate the distribution characteristics of displacement, stress, and plastic zone in the large section of open-off cut surrounding rock with stepwise excavations and supports. The reasonable support parameters were determined. Lastly, the composite beams (arches) theory, suspension theory, maximum horizontal stress theory, and strengthening surrounding rock strength theory have been proposed based on the anchorage principles of anchor bolts (cables) [18-20]. Furthermore, the active support systems of pretensioned anchor bolts and anchor cables have been widely used for ground reinforcement in roadways globally $[21,22]$.

The studies discussed above helped us in improving the understanding of the surrounding rock control principle of the large width (section) open-off cut or roadway and developing the corresponding support design. However, studies aimed at load-bearing characteristics of the anchorage structure formed in prestressed field in the surrounding rock of extra-large width open-off cut with a width of above $11 \mathrm{~m}$ are still limited. Thus, this study focuses on an $11.5 \mathrm{~m}$-wide extra-large width open-off cut of the backfill mining panel, since the largest known open-off cut width is in the Xingdong coal mine, China. In this study, the mechanical model of an anchorage rock beam bearing structure (ARBBS) is constructed and the maximum shear stress (MSS) evolution laws with different ARBBS thicknesses and spans are investigated. On this basis, the changes in stress in ARBBS under the functions of single and composite influencing factors are compared and analyzed. The cooperative control principle of the roof ARBBS and two rib anchorage bearing structures is expounded. Lastly, a combined support scheme is proposed for an $11.5 \mathrm{~m}$-wide openoff cut, and the field monitoring is conducted to evaluate the effect of the support. The study results may provide reference for other extra-large width open-off cut or roadway stability investigations and rock support design under similar engineering and geological conditions.

\section{Geological and Mining Conditions}

Xingdong coal mine is located in Xingtai City, Hebei Province, China (Figure 1(a)). The current mining seam is the No. 2 coal seam, which has a simple geological formation and lies at an average depth of $850 \mathrm{~m}$. Its average thickness and dip angle are $4.5 \mathrm{~m}$ and $9^{\circ}$, respectively. The high water content material backfill mining technology has to be studied, since more than $82 \%$ of the total mine coal reserves are buried under the villages situated in Xingdong coal mine. The 1126 panel with a $7 \mathrm{~m}$-wide open-off cut was selected for this study to examine the technology, and the success has been achieved. Afterwards, the integral installation method using the $10.4 \mathrm{~m}$-long split-type backfill mining hydraulic support (Figure 1(b)) will be applied to the 1128 panel to further improve the installation efficiency of the hydraulic support. The schematic plan of the roadways and panel of the test site is shown in Figure 1(c). A lithologic distribution of the borehole histogram of the test site is shown in Figure 2. The roof rock strata above the No. 2 coal seam are mudstone, siltstone, fine sandstone, siltstone, No. 1 coal seam, and siltstone, in ascending order, while the floor rock stratum is fine sandstone. The 1128 open-off cut, $3.8 \mathrm{~m}$ in height and $11.5 \mathrm{~m}$ in width, is driven along the roof line of the coal seam and is a type of extralarge width roadway [23]. The stability research of the open-off cut is the focus of this paper. 


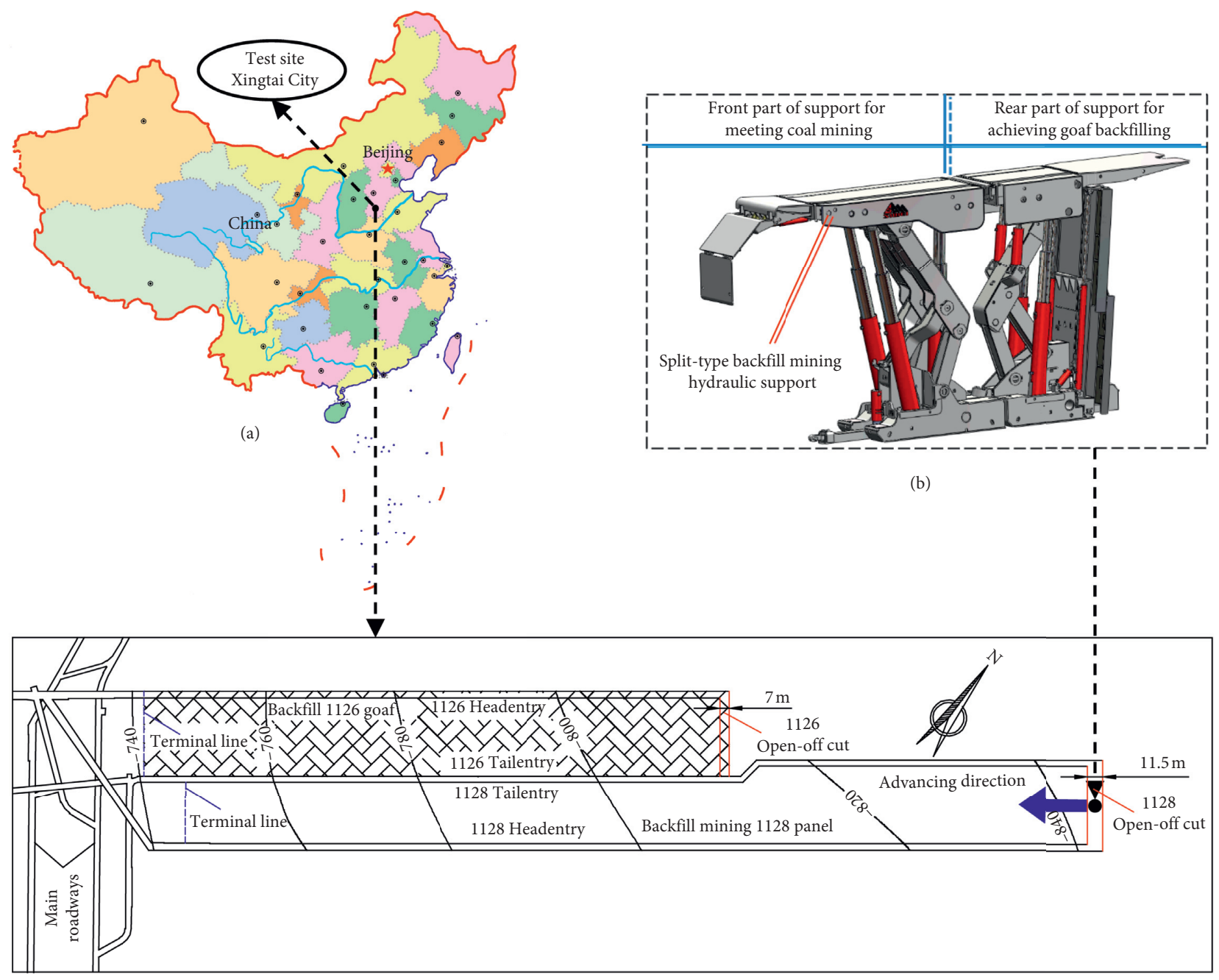

(c)

Figure 1: Mine location and panel layout of the test site. (a) Mine location. (b) Structure diagram of split-type backfill mining hydraulic support. (c) Schematic plan of roadways and panel.

\section{Roof ARBBS Formation Mechanism}

According to previous literature, the distributed effective compressive stress zone counted as the effective prestressed field is caused by the pretension and the effective compressive stress is above $0.02 \mathrm{MPa}[24,25]$. The following sections discuss the numerical modelling of the 1128 openoff cut to investigate the roof ARBBS formation mechanism based on the prestressed field distribution characteristics using FLAC3D.

3.1. Numerical Model Construction. A numerical model consisting of the Mohr-Coulomb constitutive model for the geological rock mass was generated, as shown in Figure 3. The dimensions of the model were $80 \mathrm{~m}$ (length) $\times 40 \mathrm{~m}$ (width) $\times 75 \mathrm{~m}$ (height), which were determined based on the model sensitivity analysis. Displacement in the direction perpendicular to the side boundaries was not allowed. On the basis of the laboratory tests of the samples cored from the test site, the mechanical properties of the rock mass determined by reduction calculation are listed in Table 1 [26]. Based on the production and geological conditions of the test site and field engineering experiences, the support pattern of roof anchor bolts and anchor cables used in the model is presented in Figure 3. The anchor bolts installed with a pretension of $90 \mathrm{kN}$ were $22 \mathrm{~mm}$ in diameter and $2400 \mathrm{~mm}$ in length, and the interrow spacing was $700 \mathrm{~mm} \times 800 \mathrm{~mm}$. The anchor cables installed with a pretension of $240 \mathrm{kN}$ were $21.8 \mathrm{~mm}$ in diameter and $8500 \mathrm{~mm}$ in length, and the interrow spacing was $1000 \mathrm{~mm} \times 1600 \mathrm{~mm}$. The mechanical and geometrical parameters of the "Cable" structure element are listed in Table 2 [27, 28].

3.2. Roof ARBBS Formation Mechanism Analysis. The prestressed stress distribution induced by the rock support is shown in Figure 4. The effective prestressed field in the roof is nearly rectangular along the open-off cut cross section (Figure 4(a)). Due to the interaction of anchor bolts and anchor cables, the arched high stress zone appears in the shallow surrounding rock. This transforms the stress state 


\begin{tabular}{|c|c|c|c|c|c|}
\hline Lithology description & Thickness (m) & Depth (m) & Rock stratum & & \\
\hline $\begin{array}{l}\text { Taupe gray, powder particle structure, containing } \\
\text { quartz, feldspar, and calcite (micrite) }\end{array}$ & 9.9 & 809.3 & Sandy calcarenite & & \\
\hline $\begin{array}{c}\text { Dark grey, laminar structure, containing calcite and } \\
\text { quartz sand }\end{array}$ & 11.5 & 819.2 & Sandy limestone & & \\
\hline $\begin{array}{l}\text { Dark grey, fine silty structure, containing a large } \\
\text { amount of carbonization }\end{array}$ & 3.9 & 830.7 & Siltstone & (n) & \\
\hline $\begin{array}{l}\text { Dark black, vitreous luster, massive structure, joint } \\
\text { development, uneven fracture }\end{array}$ & 0.5 & 834.6 & No.1 coal seam & & \\
\hline $\begin{array}{c}\text { Grey, containing fossil plant, massive structure, } \\
\text { horizontal bedding }\end{array}$ & 1.8 & 835.1 & Siltstone & & \\
\hline $\begin{array}{l}\text { Gray white, argillaceous cementation, low } \\
\text { strength of rock }\end{array}$ & 8.0 & 836.9 & Fine sandstone & & \\
\hline $\begin{array}{l}\text { Black grey, containing fossil plant, corrugated } \\
\text { bedding, crack development }\end{array}$ & 5.0 & 844.9 & Siltstone & & - \\
\hline White, soft, cluster by hand & 0.1 & 849.9 & Mudstone & & 7 \\
\hline $\begin{array}{l}\text { Dark black, vitreous luster, massive structure, joint } \\
\text { development, uneven fracture }\end{array}$ & 4.5 & 850.0 & No. 2 coal seam & & \\
\hline $\begin{array}{c}\text { Grey, dark material, argillaceous cementation, crack } \\
\text { development }\end{array}$ & 9.8 & 854.5 & Fine sandstone & & \\
\hline $\begin{array}{c}\text { Grey, fine-grained texture, containing feldspar, } \\
\text { siliceous cement }\end{array}$ & 20.0 & 864.3 & $\begin{array}{l}\text { Medium-grain } \\
\text { sandstone }\end{array}$ & & \\
\hline
\end{tabular}

Figure 2: Lithologic distribution of the borehole histogram of the test site.

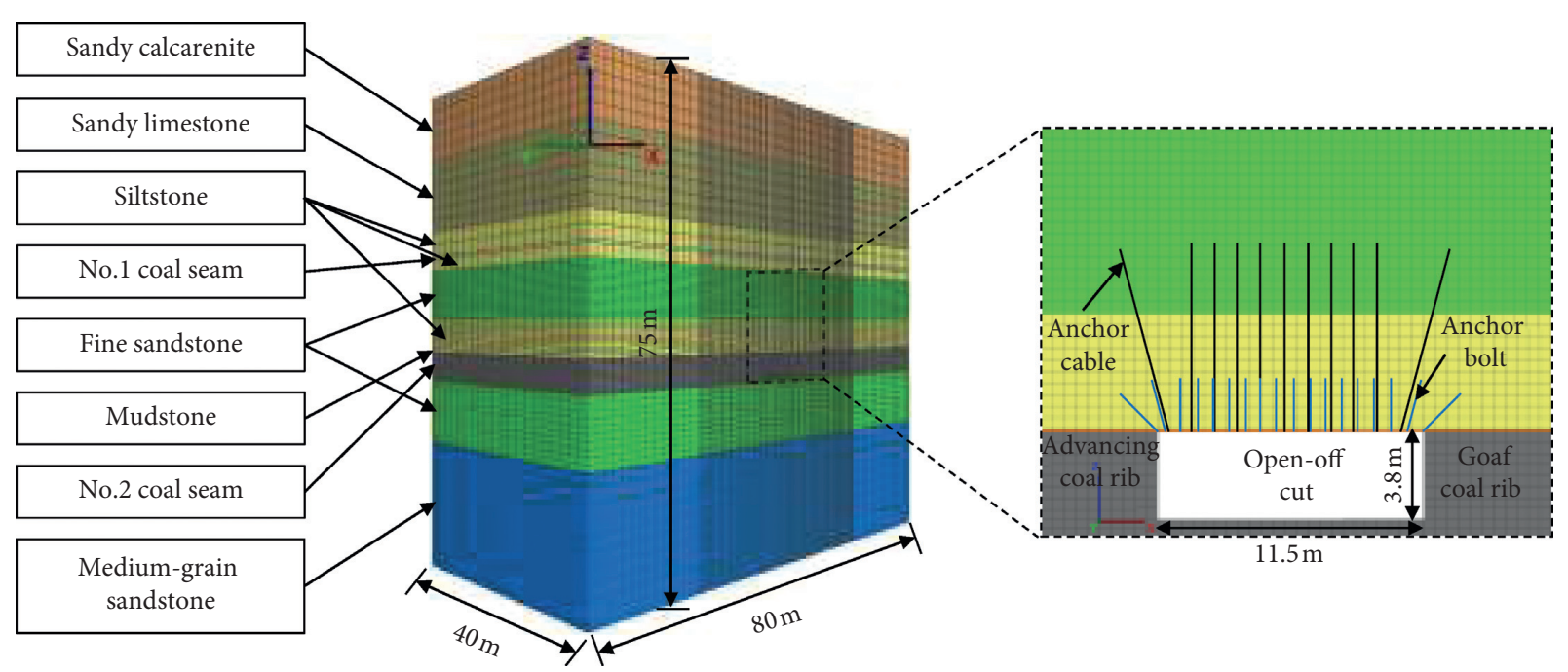

Figure 3: Configuration of the model performed using FLAC3D and support pattern of roof anchor bolts and anchor cables.

from either uniaxial stress or biaxial stress to three-dimensional stress and effectively restrains the dilatancy deformation, such as crack propagation, shearing slip, and bed separation. In addition, the prestressed stress expanding into the roof above the two coal ribs changes the stress state in this region. This controls the generation of tension strain and shear strain of the surrounding rock to increase the roof bearing capacity and prevent caving of the cutting roof along the coal wall. Consequently, the support performances of the two coal ribs are utilized greatly. Furthermore, the prestressed stress can constantly diffuse into the deep surrounding rock, where the bearing capacity of the rock mass is stronger, thereby enhancing the overall stability of the anchorage bearing structure. Thus, the roof-ribs cooperative control structure that bears most of the load of the roof can be developed to ensure a relatively low stress environment. The prestressed stress distribution along the open-off cut strike is presented in Figure 4(b). It can be observed that most of the stress isolines are nearly horizontal, and the effective prestressed field tends to be continuous and 
TABLE 1: Mechanical properties of rock mass applied in the model.

\begin{tabular}{|c|c|c|c|c|c|c|c|}
\hline Rock stratum & $\begin{array}{c}\text { Young's modulus } \\
(\mathrm{GPa})\end{array}$ & $\begin{array}{l}\text { Poisson's } \\
\text { ratio }\end{array}$ & $\begin{array}{c}\text { Tensile strength } \\
(\mathrm{MPa})\end{array}$ & $\begin{array}{c}\text { Cohesion } \\
\text { (MPa) }\end{array}$ & $\begin{array}{c}\text { Friction angle } \\
\left({ }^{\circ}\right)\end{array}$ & $\begin{array}{l}\text { Density } \\
\left(\mathrm{kg} / \mathrm{m}^{3}\right)\end{array}$ & $\begin{array}{l}\text { Thickness } \\
\text { (m) }\end{array}$ \\
\hline Sandy calcarenite & 35.6 & 0.22 & 7.2 & 12.0 & 43 & 2732 & 9.9 \\
\hline Sandy limestone & 36.5 & 0.20 & 6.9 & 12.8 & 45 & 2786 & 11.5 \\
\hline Siltstone & 21 & 0.24 & 4.5 & 8.6 & 41 & 2550 & 3.9 \\
\hline No. 1 coal seam & 3.5 & 0.31 & 1.2 & 4.1 & 23 & 1450 & 0.5 \\
\hline Siltstone & 21 & 0.24 & 4.5 & 8.6 & 41 & 2550 & 1.8 \\
\hline Fine sandstone & 33 & 0.22 & 6.3 & 11.1 & 43 & 2700 & 8.0 \\
\hline Siltstone & 21 & 0.24 & 4.5 & 8.6 & 41 & 2550 & 5.0 \\
\hline Mudstone & 14 & 0.27 & 1.9 & 6.3 & 33 & 2250 & 0.1 \\
\hline No. 2 coal seam & 3.5 & 0.31 & 1.2 & 4.1 & 23 & 1450 & 4.5 \\
\hline Fine sandstone & 33 & 0.22 & 6.3 & 11.1 & 43 & 2700 & 9.8 \\
\hline $\begin{array}{l}\text { Medium-grain } \\
\text { sandstone }\end{array}$ & 31 & 0.23 & 5.8 & 10.9 & 39 & 2650 & 20.0 \\
\hline
\end{tabular}

TABLE 2: Mechanical and geometrical parameters of "Cable" structure element.

\begin{tabular}{|c|c|c|c|c|c|c|}
\hline Type & $E(\mathrm{GPa})$ & $C_{\mathrm{g}}(\mathrm{N} / \mathrm{m})$ & $K_{\mathrm{g}}\left(\mathrm{N} / \mathrm{m}^{2}\right)$ & $\rho_{\mathrm{g}}(\mathrm{m})$ & $\mathrm{A}\left(\mathrm{m}^{2}\right)$ & $F_{\mathrm{t}}(\mathrm{N})$ \\
\hline Roof anchor bolt & 200 & $4.9 \mathrm{e} 5$ & $6.7 \mathrm{e} 9$ & $9.54 \mathrm{e}-2$ & $3.80 \mathrm{e}-4$ & $1.9 \mathrm{e} 5$ \\
\hline Roof anchor cable & 195 & $4.9 \mathrm{e} 5$ & $5.6 \mathrm{e} 9$ & $9.54 \mathrm{e}-2$ & $3.73 e-4$ & $4.1 \mathrm{e} 5$ \\
\hline
\end{tabular}

Note. $E=$ Young's modulus; $C_{\mathrm{g}}=$ grout cohesive strength per unit length; $K_{\mathrm{g}}=$ grout stiffness per unit length; $\rho_{\mathrm{g}}=$ grout exposed perimeter; $A=$ cross-sectional area; $F_{\mathrm{t}}=$ tensile yield force.

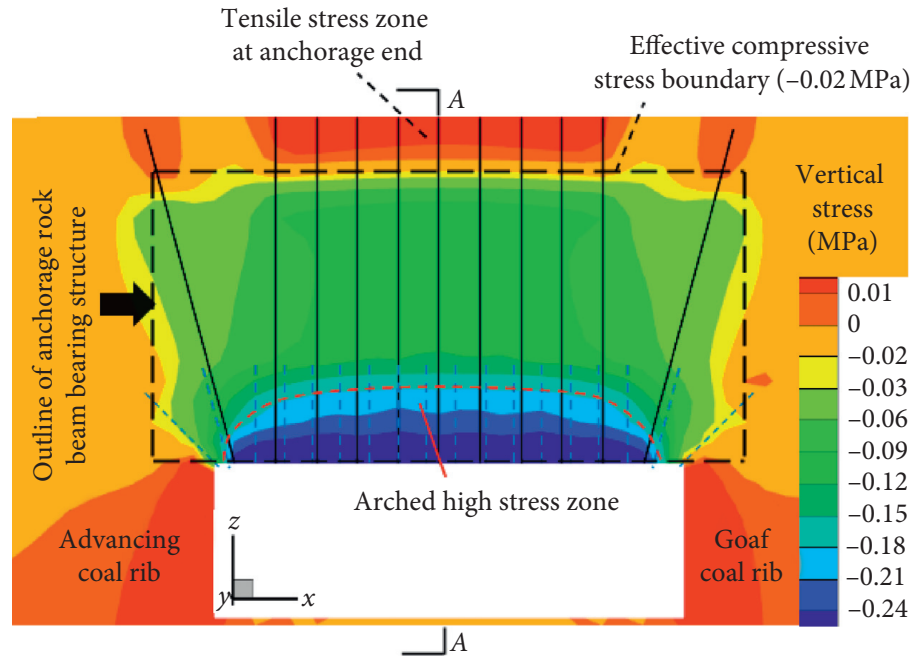

(a)

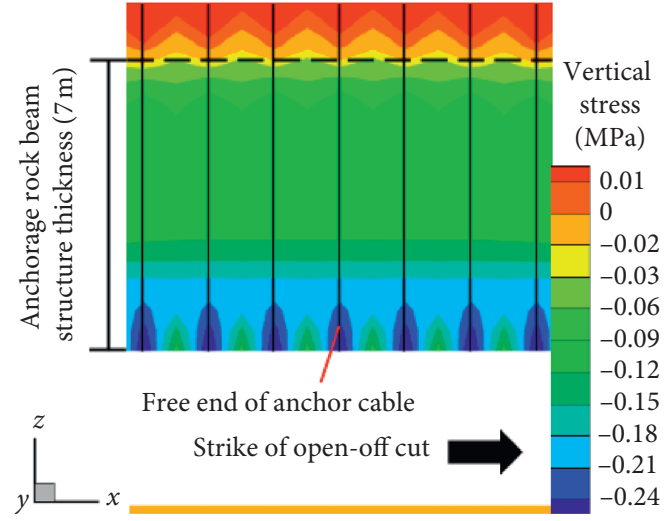

(b)

Figure 4: Prestressed stress distribution in open-off cut roof under the roof anchor bolts and anchor cables support. (a) Cross section. (b) Strike (cross section A-A in Figure 4(a)).

uniform. However, the arched high stress isolines are distributed densely around the free end of the anchor cables, where the stress concentration is comparatively high. Consequently, the surface protecting components should be used to spread the prestressed stress to a larger section of the rock surface and to reduce the pretension loss, further improving the active support effect.

The prestressed stress distribution at different horizontal distances of the roof with varying depths was recorded and is plotted in Figure 5. The layout of the measuring lines is presented in Figure 5(a). It can be observed that as the roof depth increases, the stress distribution gradually shifts from approximately groove shape to approximately inverted groove shape (Figure 5(b)). Furthermore, when the roof depth increases from $0.6 \mathrm{~m}$ to $7.1 \mathrm{~m}$, the stress can be seen to vary from -0.31 to $-0.02 \mathrm{MPa}$, indicating the effective compressive stress in the surrounding rock. Additionally, low tensile stress is found in the surrounding rock when the roof depth is above $7.1 \mathrm{~m}$. 


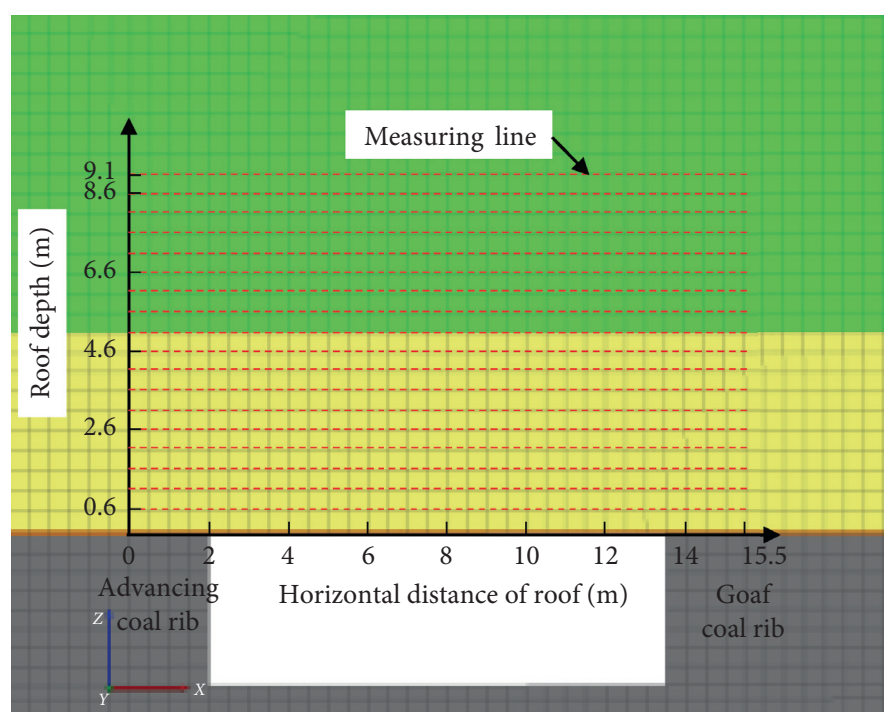

(a)

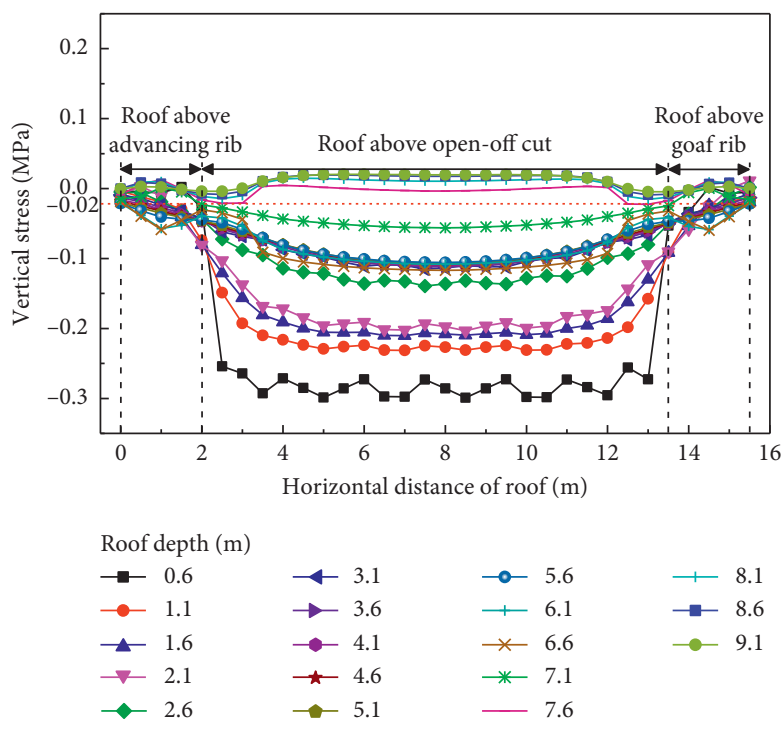

(b)

Figure 5: Prestressed stress distribution at different horizontal distances of the roof with varying depths. (a) Layout of measuring lines in Figure 4(a). (b) Prestressed stress distribution curves.

According to the foregoing analysis, the high pretensioned anchor bolts and anchor cables with the surface protecting components can significantly expand the prestressed field distribution area, strengthen its continuity and uniformity, and enhance the support strength. Thus, the effective anchorage area of the roof can meet the plane strain assumption of a beam and can be regarded as a rock beam structure for further research. The three-dimensional distribution of the approximately $7 \mathrm{~m}$-thick ARBBS in the 1128 open-off cut roof is depicted in Figure 6.

\section{Mechanical Analysis of Roof ARBBS Model}

4.1. Roof ARBBS Model Construction. Figure 7 depicts the ARBBS model constructed by combining the aforementioned simulation results and production and geological conditions of the test site. To simplify the calculations without compromising the accuracy, the basic assumptions made were as follows:

(a) The effective anchorage area of the roof under the high pretensioned roof anchor bolts and anchor cables support can be regarded as a whole continuous rock beam structure. It is nearly rectangular along the open-off cut cross section. The model is prepared under the plane strain state and is unit width along the open-off cut strike. Its advancing end and goaf end are simplified to the clamped boundaries.

(b) The model is loaded by itself and upper soft rock mass [29], and its thickness $h$ is the effective anchorage thickness of the roof. Forces $R_{\mathrm{A}}$ and $R_{\mathrm{B}}$ are exerted by the coal at both ends of the model because of unstable triangular block formation in the coal rib due to the shear failure. The concentrated force $F$ is exerted by the single hydraulic prop. The action area

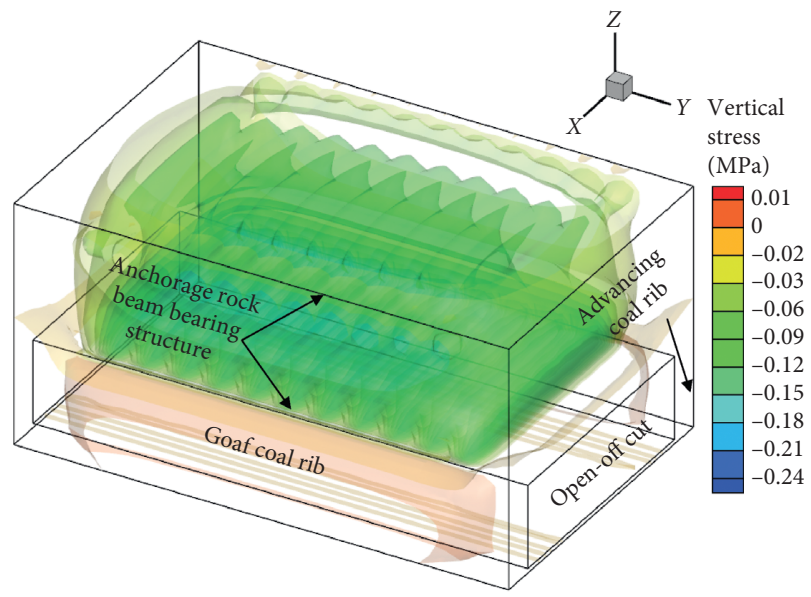

FIGURE 6: Three-dimensional distribution of the ARBBS in openoff cut roof.

of the anchor cable has the range of its interrow spacing, and the support strength $p$ is provided by the roof anchor cables. The support action of the anchor cables is realized by transferring the tensile force of the anchor cables to the surrounding rock surface through the plate, steel beam, steel strip, and so forth [30-33].

In Figure 7, $a$ is the width of the open-off cut, $b$ is the horizontal distance between the action boundary of the anchor cables and the coordinate origin at the goaf end, $c$ is the maximum width of the unstable triangular block, $d$ is the horizontal distance between the action boundary of the anchor cables and the coordinate origin at the advancing end, $e$ is the distance between the single hydraulic prop and the goaf coal wall, $h_{0}$ is the height of the open-off cut, $l$ is the span of the model, $M_{\mathrm{A}}$ and $M_{\mathrm{B}}$ are the bending moments at 


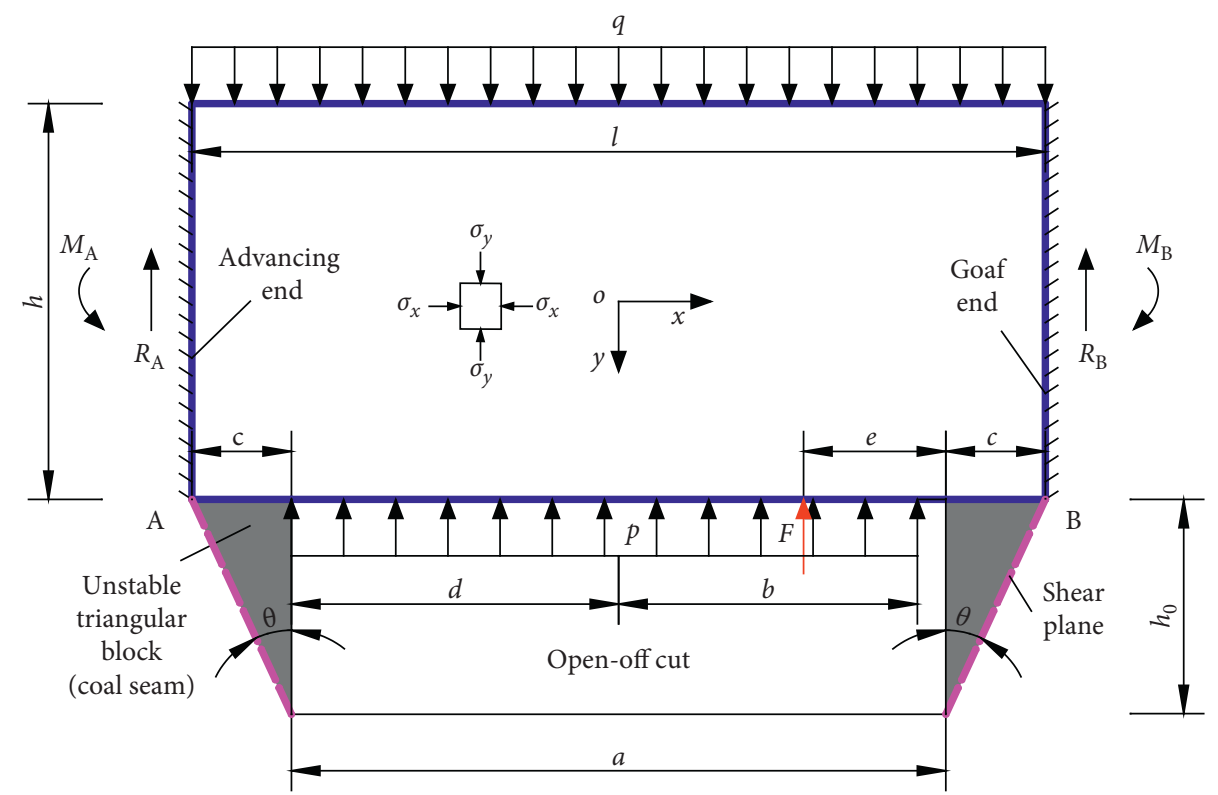

FIGURE 7: ARBBS model in open-off cut roof.

both ends, $q$ is the roof load, $\theta$ is the shear failure angle of the coal, and $\sigma_{x}$ and $\sigma_{y}$ are the horizontal and vertical stress components of the model element, respectively.

According to [18], $q$ is given as follows:

$$
q=\left(\frac{E_{1} h_{1}^{3}\left(\gamma_{1} h_{1}+\gamma_{2} h_{2}+\cdots+\gamma_{n} h_{n}\right)}{E_{1} h_{1}^{3}+E_{2} h_{3}^{3}+\cdots+E_{n} h_{n}^{3}}\right) .
$$

Here, $E_{n}$ is Young's modulus of the $n$th layer above the open-off cut, $\gamma_{n}$ is unit weight of the nth layer, and $h_{n}$ is the thickness of the $n$th layer.

According to Protojiakonov's theory, $p, \theta, c$, and $l$ are given as follows $[34,35]$ :

$$
\begin{aligned}
& p=\frac{F^{\prime}}{m^{\prime} n^{\prime}}, \\
& \theta=\left(45^{\circ}-\left(\frac{\varphi_{0}}{2}\right)\right), \\
& c=h_{0} \tan \theta \\
& l=a+2 h_{0} \tan \left(45^{\circ}-\left(\frac{\varphi_{0}}{2}\right)\right) .
\end{aligned}
$$

Here, $F^{\prime}$ is the anchoring force of the anchor cables; $m^{\prime}$ and $n^{\prime}$ are the interrow spacing of the anchor cables; and $\varphi_{0}$ is the friction angle of the interface between the coal seam and rock stratum.

\subsection{Theoretical Derivation of Maximum Shear Stress (MSS) in} Roof ARBBS Model. According to previous literature, the shear failure is the main failure in the ARBBS [36, 37]. Hence, it is proposed that the MSS can be taken as the mechanical index for assessing ARBBS stability. It can be seen that the roof load, single hydraulic prop, and anchor cable are closely related to ARBBS stability. The MSS in the
ARBBS is derived under the functions of these influencing factors based on the stress superposition principle [24].

The stress components in the ARBBS under the function of $q$ are given as follows [38]:

$$
\left\{\begin{array}{l}
\sigma_{x 1}=\frac{q l^{2}}{2 h^{3}} y-\frac{6 q}{h^{3}} x^{2} y+\frac{4 q}{h^{3}} y^{3}-\frac{3 q(2+\mu)}{2 h} y-\frac{\mu q}{2} \\
\sigma_{y 1}=\frac{3 q}{2 h} y-\frac{2 q}{h^{3}} y^{3}-\frac{q}{2} \\
\tau_{x y 1}=\frac{6 q}{h^{3}} x y^{2}-\frac{3 q}{2 h} x .
\end{array}\right.
$$

Here, $\sigma_{x 1}, \sigma_{y 1}$, and $\tau_{x y 1}$ are the horizontal, vertical, and shear stress components in the ARBBS under the function of $q$, respectively, and $\mu$ is Poisson's ratio.

Then, the stress components, including the horizontal stress $\left(\sigma_{x 2}^{\prime}\right)$, vertical stress $\left(\sigma_{y 2}^{\prime}\right)$, and shear stress $\left(\tau_{x y 2}^{\prime}\right)$, under the function of $F$ are given as follows:

$$
\left\{\begin{array}{l}
\sigma_{x 2}^{\prime}=\frac{-2 F x_{2}^{2} y_{2}}{\pi\left(x_{2}^{2}+y_{2}^{2}\right)^{2}}, \\
\sigma_{y 2}^{\prime}=\frac{-2 F y_{2}^{3}}{\pi\left(x_{2}^{2}+y_{2}^{2}\right)^{2}}, \\
\tau_{x y 2}^{\prime}=\frac{-2 F x_{2} y_{2}^{2}}{\pi\left(x_{2}^{2}+y_{2}^{2}\right)^{2}} .
\end{array}\right.
$$

Here, $\left(x_{2}, y_{2}\right)$ is the coordinate.

However, coordinate transformation is needed first because the position of the coordinate origin in the model is 
different from that mentioned in equation (7). Thus, $x_{2}$ and $y_{2}$ are expressed as follows:

$$
\left\{\begin{array}{l}
x_{2}=x+c+e-\frac{l}{2} \\
y_{2}=-y+\frac{h}{2}
\end{array}\right.
$$

The reactions caused by $F$ at the ends of ARBBS are given as follows:

$$
\left\{\begin{array}{l}
\mathrm{R}_{A 2}=\frac{F(c+e)^{2}(3 l-2 c-2 e)}{l^{3}}, \\
\mathrm{R}_{B 2}=\frac{F(l-c-e)^{2}(l+2 c+2 e)}{l^{3}} .
\end{array}\right.
$$

Here, $R_{A 2}$ and $R_{B 2}$ are the reactions at the advancing end and goaf end of ARBBS, respectively.

The stress components in the ARBBS under the function of $F$ are given as follows by integrating equations (7), (8), and (9):

$$
\left\{\begin{aligned}
\sigma_{x 2} & =\frac{2 F}{\pi}\left(-y+\left(\frac{h}{2}\right)\right)\left\{\frac{(x+c+e-(l / 2))^{2}}{\left[(x+c+e-(l / 2))^{2}+(-y+(h / 2))^{2}\right]^{2}}-\frac{(c+e)^{2}(3 l-2 c-2 e)(x-(l / 2))^{2}}{\left[(x+(l / 2))^{2}+(-y+(h / 2))^{2}\right]^{2} l^{3}}\right. \\
& \left.-\frac{(l-c-e)^{2}(l+2 c+2 e)(x+(l / 2))^{2}}{\left[(x-(l / 2))^{2}+(-y+(h / 2))^{2}\right]^{2} l^{3}}\right\}, \\
\sigma_{y 2} & =\frac{2 F}{\pi}\left(-y+\left(\frac{h}{2}\right)\right)^{3}\left\{\frac{1}{\left[(x+c+e-(l / 2))^{2}+(-y+(h / 2))^{2}\right]^{2}}-\frac{(c+e)^{2}(3 l-2 c-2 e)}{\left[(x+(l / 2))^{2}+(-y+(h / 2))^{2}\right]^{2} l^{3}}\right. \\
- & \left.\frac{(l-c-e)^{2}(l+2 c+2 e)}{\left.\left[(x-(l / 2))^{2}+(-y+(h / 2))^{2}\right]^{2} l^{3}\right\}}\right\} \\
\tau_{x y 2} & =\frac{2 F}{\pi}\left(-y+\left(\frac{h}{2}\right)\right)^{2}\left\{\frac{(x+c+e-(l / 2))}{\left[(x+c+e-(l / 2))^{2}+(-y+(h / 2))^{2}\right]^{2}}-\frac{(c+e)^{2}(3 l-2 c-2 e)(x+(l / 2))}{\left[(x+(l / 2))^{2}+(-y+(h / 2))^{2}\right]^{2} l^{3}}\right. \\
& \left.-\frac{(l-c-e)^{2}(l+2 c+2 e)(x-(l / 2))}{\left[(x-(l / 2))^{2}+(-y+(h / 2))^{2}\right]^{2} l^{3}}\right\},
\end{aligned}\right.
$$

Here, $\sigma_{x 2}, \sigma_{y 2}$, and $\tau_{x y 2}$ are the horizontal, vertical, and shear stress components in ARBBS under the function of $F$, respectively.
Additionally, the stress components, including the horizontal stress $\left(\sigma_{x 3}^{\prime}\right)$, vertical stress $\left(\sigma_{y 3}^{\prime}\right)$, and shear stress $\left(\tau_{x y 3}^{\prime}\right)$, under the function of $p$ are given as follows: 


$$
\left\{\begin{array}{l}
\left(\sigma_{x 3}^{\prime}\right)=\left(\frac{-2}{\pi}\right) \int_{-d}^{b} \frac{p\left(x_{3}-\xi\right)^{2} y_{3} \mathrm{~d} \xi}{\left[\left(\left(x_{3}-\xi\right)^{2}+y_{3}^{2}\right)\right]^{2}}, \\
\left(\sigma_{y 3}^{\prime}\right)=\left(\frac{-2}{\pi}\right) \int_{-d}^{b} \frac{p y_{3}^{3} \mathrm{~d} \xi}{\left[\left(\left(x_{3}-\xi\right)^{2}+y_{3}^{2}\right)\right]^{2}}, \\
\left(\tau_{x y 3}^{\prime}\right)=\left(\frac{-2}{\pi}\right) \int_{-d}^{b} \frac{p\left(x_{3}-\xi\right)^{2} y_{3}^{2} \mathrm{~d} \xi}{\left[\left(\left(x_{3}-\xi\right)^{2}+y_{3}^{2}\right)\right]^{2}} .
\end{array}\right.
$$

Here, $\xi$ and $\mathrm{d} \xi$ are the abscissa at any point within the action range of the anchor cables and corresponding length, respectively, and $\left(x_{3}, y_{3}\right)$ is the coordinate.
It can be seen that the coordinate transformation is also needed here because the position of the coordinate origin in the model is different from that mentioned in equation (11). Thus, $x_{3}$ and $y_{3}$ are expressed as follows:

$$
\left\{\begin{array}{l}
\mathrm{x}_{3}=x \\
y_{3}=-y+\left(\frac{h}{2}\right)
\end{array}\right.
$$

The reactions caused by $p$ at the ends of ARBBS are given as follows:

$$
\left\{\begin{array}{l}
R_{A 3}=\frac{p(b+d)}{4 l^{3}}\left[3(2 l-2 s-b-d)^{2} l-(2 l-2 s-b-d)^{3}+(b+d)^{2} l-(2 l-2 s-b-d)(b+d)^{2}\right] \\
R_{B 3}=\frac{p(b+d)\left(4 l^{3}-1\right)}{4 l^{3}}\left[3(2 l-2 s-b-d)^{2} l-(2 l-2 s-b-d)^{3}+(b+d)^{2} l-(2 l-2 s-b-d)(b+d)^{2}\right] .
\end{array}\right.
$$

Here, $R_{A 3}$ and $R_{B 3}$ are the reactions at the advancing end and goaf end of ARBBS, respectively, and $s$ is the distance between the action boundary of the anchor cables and the advancing end of ARBBS.
Similarly, the stress components in the ARBBS under the function of $p$ are given as follows by integrating equations (11), (12), and (13):

$$
\left\{\begin{array}{l}
\sigma_{x 3}=\frac{p}{\pi}\left[\arctan \left(\frac{x+d}{-y+(h / 2)}\right)-\arctan \left(\frac{x-b}{-y+(h / 2)}\right)-\frac{(x+d)(-y+(h / 2))}{(x+d)^{2}+(-y+(h / 2))^{2}}+\frac{(x-b)(-y+(h / 2))}{(x-b)^{2}+(-y+(h / 2))^{2}}\right] \\
-\frac{2}{\pi}\left(-y+\frac{h}{2}\right)\left\{\frac{R_{A 3}\left(x+(1 / 2)^{2}\right)}{\left[(x-(1 / 2))^{2}+(-y+(h / 2))^{2}\right]^{2}}+\frac{R_{B 3}\left(x-(1 / 2)^{2}\right)}{\left[(x-(1 / 2))^{2}+(-y+(h / 2))^{2}\right]^{2}}\right\}, \\
\sigma_{y 3}=\frac{p}{\pi}\left[\arctan \left(\frac{x+d}{-y+(h / 2)}\right)-\arctan \left(\frac{x-b}{-y+(h / 2)}\right)+\frac{(x+d)(-y+(h / 2))}{(x+d)^{2}+(-y+(h / 2))^{2}}-\frac{(x-b)(-y+(h / 2))}{(x-b)^{2}+(-y+(h / 2))^{2}}\right] \\
-\frac{2}{\pi}\left(-y+\frac{h}{2}\right)^{3}\left\{\frac{R_{A 3}}{\left[(x-(1 / 2))^{2}+(-y+(h / 2))^{2}\right]^{2}}+\frac{R_{B 3}}{\left[(x-(1 / 2))^{2}+(-y+(h / 2))^{2}\right]^{2}}\right\}, \\
\tau_{x y 3}=-\frac{p}{\pi}\left[\frac{(-y+(h / 2))^{2}}{(x+d)^{2}+(-y+(h / 2))^{2}}+\frac{(-y+(h / 2))^{2}}{(x-b)^{2}+(-y+(h / 2))^{2}}\right] \\
-\frac{2}{\pi}\left(-y+\frac{h}{2}\right)^{2}\left\{\frac{R_{A 3}(x+(1 / 2))}{\left[(x-(1 / 2))^{2}+(-y+(h / 2))^{2}\right]^{2}}-\frac{R_{B 3}(x-(1 / 2))}{\left[(x-(1 / 2))^{2}+(-y+(h / 2))^{2}\right]^{2}}\right\} .
\end{array}\right.
$$


Here, $\sigma_{x 3}, \sigma_{y 3}$, and $\tau_{x y 3}$ are the horizontal, vertical, and shear stress components in ARBBS under the function of $p$, respectively.
According to the foregoing theoretical derivation, the MSS in the ARBBS under the functions of $q, F$, and $p$ is given by

$$
\tau_{\max }=\left[\left(\frac{\sigma_{y 1}+\sigma_{y 2}+\sigma_{y 3}-\sigma_{x 1}-\sigma_{x 2}-\sigma_{x 3}}{2}\right)^{2}+\left(\tau_{x y 1}+\tau_{x y 2}+\tau_{x y 3}\right)^{2}\right]^{(1 / 2)}
$$

Here, $\tau_{\max }$ is the MSS in ARBBS under the functions of $q$, $F$, and $p$.

Substituting equations (6), (10), and (14) into equation (15), $\tau_{\max }$ is calculated as

\section{Engineering Application of Roof ARBBS Model in Extra-Large Width Open-Off Cut}

5.1. Main Parameters of ARBBS Model. To demonstrate the aforementioned mechanical analysis results, the support design of the 1128 extra-large width open-off cut is conducted. According to the production and geological conditions of the test site, laboratory testing results [39-41], aforementioned simulation results, and field engineering practices, the main parameters are determined as follows: $a=11.5 \mathrm{~m}, \quad b=5.25 \mathrm{~m}, c=1.75 \mathrm{~m}, \quad d=5.75 \mathrm{~m}, \quad e=2.5 \mathrm{~m}$, $s=1.75 \mathrm{~m}, h_{0}=3.8 \mathrm{~m}, \varphi_{0}=40.5^{\circ}, F=250 \mathrm{kN}, F^{\prime}=300 \mathrm{kN}$, $\mu=0.23, m^{\prime}=1 \mathrm{~m}$, and $n^{\prime}=1.6 \mathrm{~m}$. The unit weights of the coal seam, mudstone, siltstone, fine sandstone, sandy limestone, and sandy calcarenite are $14.5 \mathrm{kN} / \mathrm{m} 3,22.5 \mathrm{kN} /$ $\mathrm{m}^{3}, 25.5 \mathrm{kN} / \mathrm{m}^{3}, 27 \mathrm{kN} / \mathrm{m}^{3}, 27.86 \mathrm{kN} / \mathrm{m}^{3}$, and $27.32 \mathrm{kN} / \mathrm{m}^{3}$, respectively. Then Young's modulus and thickness of these rock strata can be known from Table 1 . By substituting the parameters of these rock strata into equation (1), $q=325 \mathrm{kN} /$ $\mathrm{m}$ can be obtained according to $\left(q_{\mathrm{n}+1}\right) 1<\left(q_{n}\right) 1$. According to the aforementioned numerical simulation results, the ARBBS thickness $h$ is $7 \mathrm{~m}$ (Figure 4). The anchoring force $F^{\prime}$ of the roof anchor cable is determined by the pullout test of the anchor cable. According to equations (2) and (5), $p$ and $l$ are given as follows:

(i) $p=300 \mathrm{kN} /(1 \mathrm{~m} \times 1.6 \mathrm{~m})=187.5 \mathrm{kPa}$

(ii) $l=11.5 \mathrm{~m}+2 \times 3.8 \mathrm{~m} \times \tan \left(45^{\circ}-40.5^{\circ} / 2\right)=15 \mathrm{~m}$

MATLAB software is used to solve equation (15) based on these parameters. The MSS distribution laws are taken into account to study surrounding rock control principle of the extra-large width open-off cut assuming that the low stress is less than $0.1 \mathrm{MPa}$ and the high stress is greater than $0.4 \mathrm{MPa}$ in ARBBS. The research can provide the insight and reference for determining the appropriate support scheme.

\subsection{Thickness and Span Effects of ARBBS Stability}

5.2.1. Thickness Effect of ARBBS Stability. According to the aforementioned prestressed field distribution characteristics, the roof anchor cable length is closely related to the ARBBS thickness. To determine the reasonable anchor cable length, MSS distribution laws with different ARBBS thicknesses $(l=15 \mathrm{~m})$ are investigated by ignoring $F$, as shown in Figures 8 and 9 .

Figure 8 shows the MSS distributions with different ARBBS thicknesses. It can be observed that when $h$ is $3 \mathrm{~m}$ (Figure 8(a)), mainly a high stress zone exists, and the stress concentration at the corners of ARBBS is higher. The arcshaped high stress zones at the upper and lower surfaces of ARBBS appear in the asymmetric distribution along the thickness centerline $(h / 2=1.5 \mathrm{~m})$. In contrast, the smallscale low stress zones exhibit the circular distribution at its center and arc-shaped distribution at its upper surface, respectively. In this situation, the overall stability of ARBBS is relatively low, resulting in the shear deformation of the rock mass. It can also be observed that when $h$ increases from 3 to $9 \mathrm{~m}$ (Figures $8(\mathrm{a})-8(\mathrm{~d})$ ), the high stress zone constantly contracts towards both sides of ARBBS and the stress concentration rapidly reduces. The peak stress decreases from 2.47 to $0.574 \mathrm{MPa}$ (76.8\% reduction). On the other hand, the low stress zone distribution mainly exists as small-scale circular stress zone and arc-shaped stress zones, through stress zone, stress contraction zone, and elliptical stress contraction zone, in this order. It can be noted from Figure 9 that the stress exhibits a funnel-shaped distribution and the decreasing rate of the stress gradually decreases at the thickness centerline $(h / 2)$ with an increase in the thickness. To summarize, the stress state in ARBBS improves with increasing thickness to effectively reduce the deformation and failure of the rock mass caused by relatively high shear stress, especially in the shallow surrounding rock. This contributes to maintaining the integrity and stability of the roof.

To further investigate the thickness effect of ARBBS stability, the area ratio ( $n \%)$, that is, the ratio of either the low or high stress zone area to the total area in the ARBBS, is obtained by using MATLAB image binarization (Figure 10). It can be observed that when $h$ increases from 3 to $5 \mathrm{~m}$, the area ratio of the low stress zone rapidly increases with the maximum area ratio being $23.71 \%$. When $h$ increases from 5 to $10 \mathrm{~m}$, the area ratio of the low stress zone slowly decreases. On the other hand, the area ratio of the high stress zone decreases exponentially from $63.50 \%$ to $4.81 \%$ when $h$ increases from 3 to $10 \mathrm{~m}$. This indicates that increasing $h$ can restrain the shear strain of the rock mass but reduce the prestressed stress diffusion effect [24]. Evidently, reasonable $h$ is found to be $6-8 \mathrm{~m}$, implying that using the $8.5 \mathrm{~m}$-long anchor cable to support the 1128 open-off cut roof is relatively rational and reliable. $h$ in this situation is $7 \mathrm{~m}$ according to the aforementioned simulation results. 


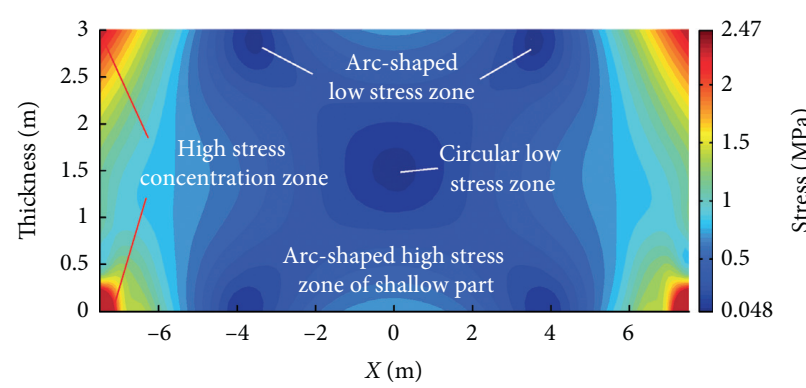

(a)

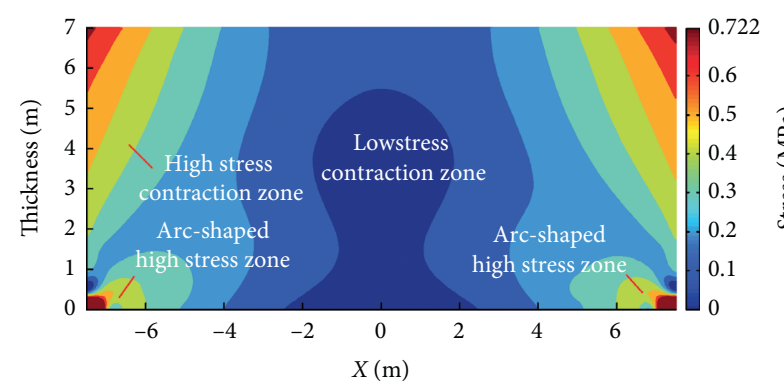

(c)

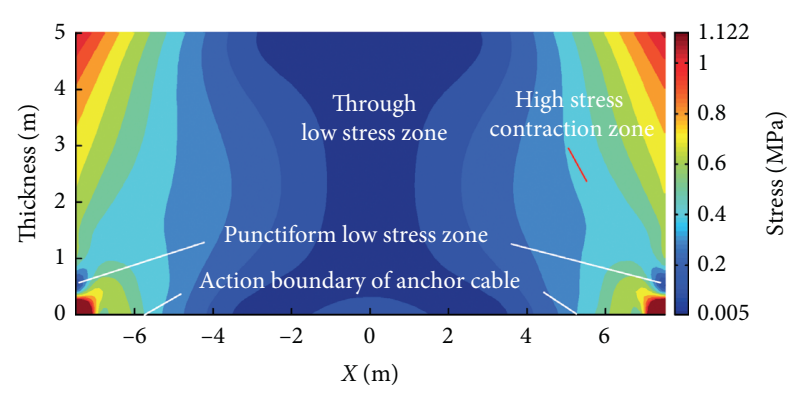

(b)

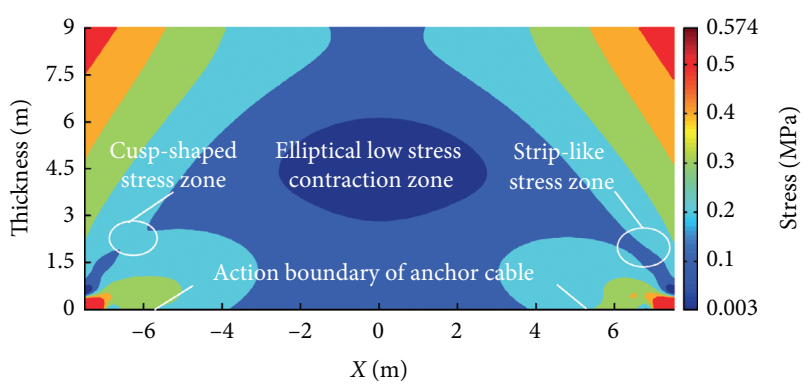

(d)

Figure 8: MSS distributions with different ARBBS thicknesses. (a) $h=3 \mathrm{~m}$, (b) $h=5$ (m), (c) $h=7$ (m), and (d) $h=9 \mathrm{~m}$.

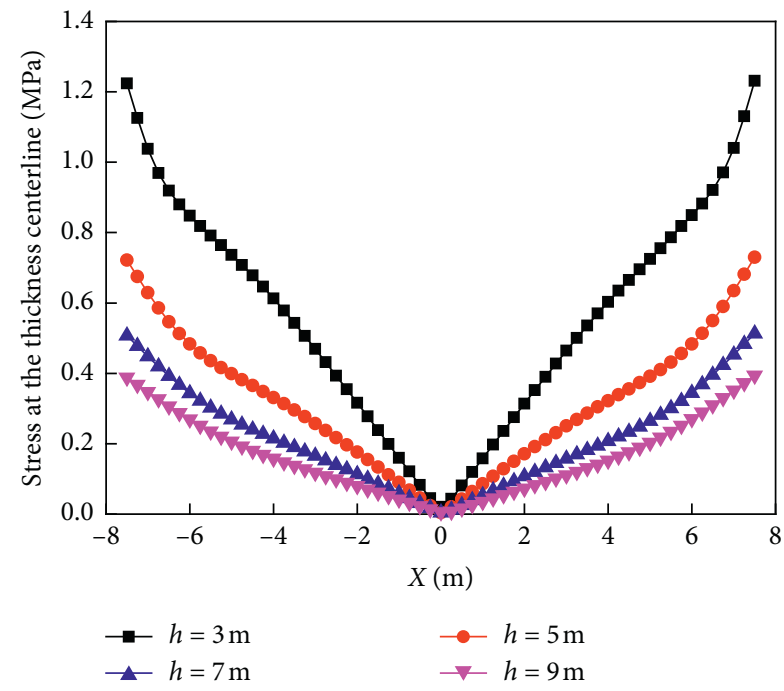

FIGURE 9: MSS distributions at the thickness centerline $(h / 2)$ with different ARBBS thicknesses.

5.2.2. Span Effect of ARBBS Stability. Previous studies demonstrated that ARBBS span has significant impact on the stress distribution and surrounding rock deformation [10]. The MSS distribution laws with different ARBBS spans $(h=7 \mathrm{~m})$ are investigated by ignoring $F$, as depicted in Figures 11 and 12.

Figure 11 shows the MSS distributions with different ARBBS spans. It can be observed that when $l$ is $9 \mathrm{~m}$ (Figure 11(a)), mainly lower stress zone (less than $0.4 \mathrm{MPa}$ ) exists and the low stress zone appears as a flattened distribution at the center of the ARBBS. In contrast, the small-scale high stress zones appear at the corners of the ARBBS, which indicate

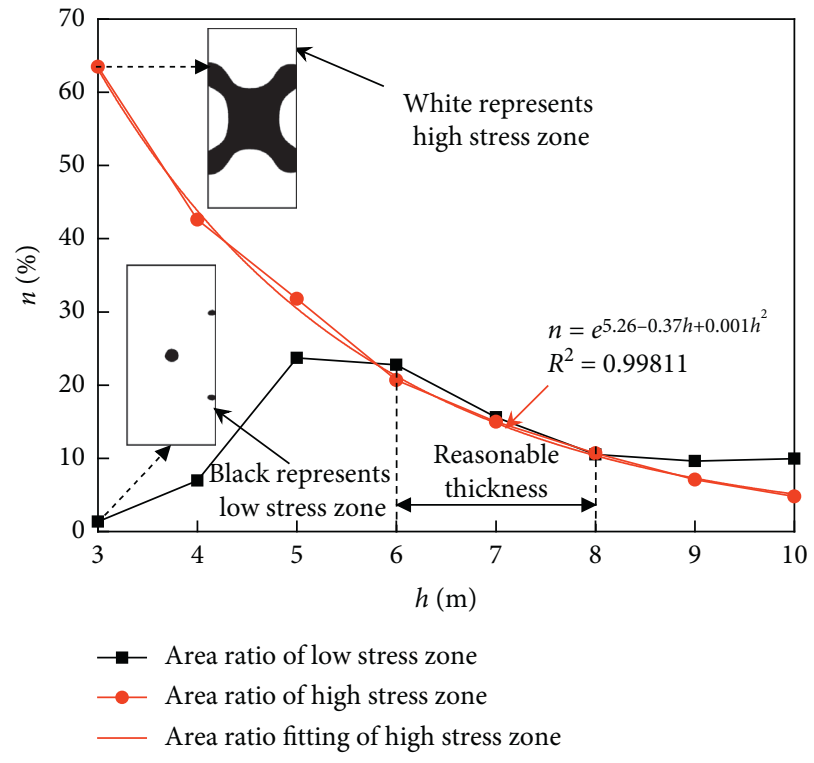

FIGURE 10: Area ratio distributions of low and high stress zones in ARBBS with different thicknesses.

its relatively better overall stability. When $l$ increases from 9 to $17 \mathrm{~m}$ (Figures 11(a)-11(c)), the high stress zone that appears in the inclined strip-like distribution constantly expands towards the center of the ARBBS and the stress concentration continuously increases. This reflects that the stress state in the ARBBS tends to deteriorate, thus resulting in the shear deformation of the rock mass. Meanwhile, the low stress zone can also be seen to expand constantly until the through low stress zone appears, implying relatively better rock mass stability in the region. Additionally, it should be mentioned that, with an increase in 


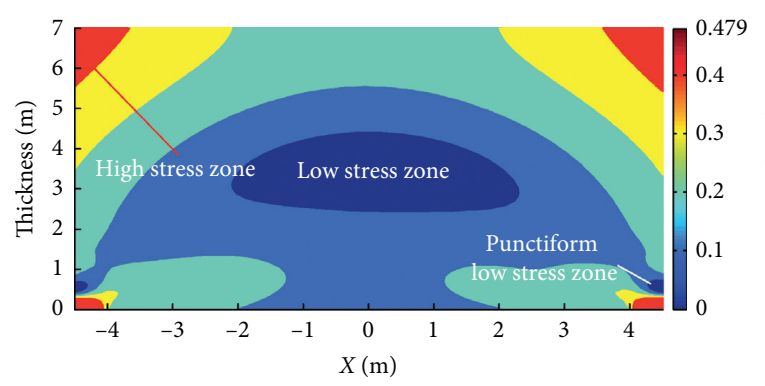

(a)

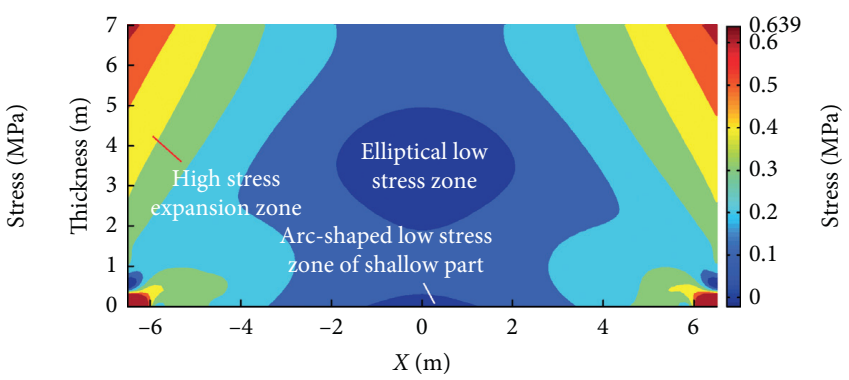

(b)

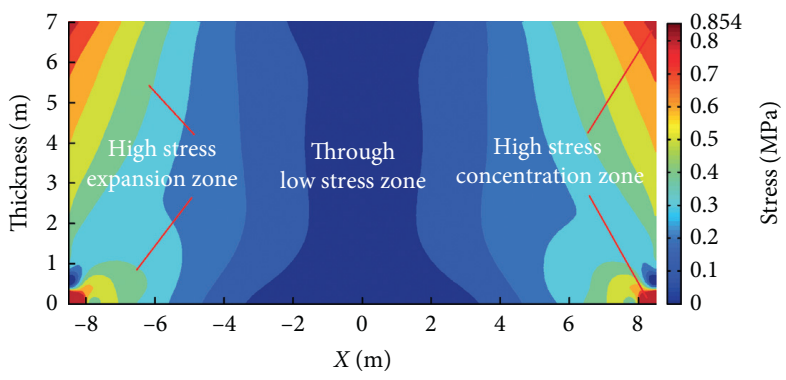

(c)

Figure 11: MSS distributions with different ARBBS spans. (a) $l=9(\mathrm{~m}),(\mathrm{b}) l=13(\mathrm{~m})$, and (c) $l=17 \mathrm{~m}$.

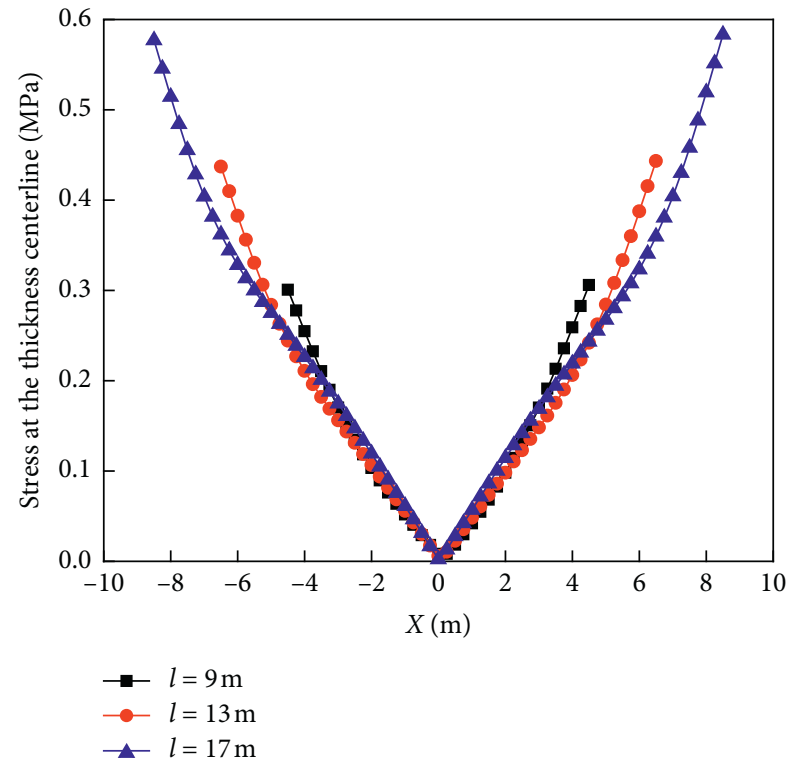

FIGURE 12: MSS distributions at the thickness centerline $(h / 2)=3.5$ (m) with different ARBBS spans.

the span, the stress exhibits a V-shaped distribution and significantly increases at the thickness centerline $(h / 2=3.5 \mathrm{~m})$, as shown in Figure 12.

To further investigate the span effect of ARBBS stability, the area ratio $(n \%)$ distributions of the low and high stress zones in the ARBBS with different spans are prepared by MATLAB image binaryzation, as depicted in Figure 13. It can be observed that when $l$ increases from 7 to $17 \mathrm{~m}$, the area ratio distribution of the low stress zone appears in the inclined " $\sqrt{ }$ " pattern and the range of the area ratio is found to be $9.86-22.05 \%$. On the other hand, the area ratio distribution of the high stress zone is fitted by the cubic function and the area ratio rapidly increases from $0.60 \%$ to $19.34 \%$. This reflects that increasing $l$ can severely affect the overall stability of the ARBBS. Thus, the shearing slip, bed separation, and roof fall tend to occur in the roof. Accordingly, it becomes necessary to adopt the method of multiple excavations to form the open-off cut to further restrain the roof sag, especially for the extra-large width open-off cut. Simultaneously, it should be noted that the pretensioned high-strength rib anchor bolt and anchor cable can be applied to reinforce the coal rib, thereby preventing an increase in the ARBBS span.

\subsection{Surrounding Rock Control Principle}

5.3.1. Reducing-Span Effect of High Working Resistance Single Hydraulic Prop and High-Strength Roof Anchor Cables and Anchor Bolts Support Principle. As discussed earlier, the roof load, single hydraulic prop, and anchor cable are closely related to the ARBBS stability. The MSS distribution characteristics in the ARBBS, $7 \mathrm{~m}$ in thickness and $15 \mathrm{~m}$ in span, are investigated under the functions of these influencing factors, as shown in Figure 14 and listed in Table 3.

When $q$ acts on the ARBBS (Figure 14(a)), the high stress zone with an area ratio of $23.78 \%$ appears as the inclined strip-like distribution on both sides of the ARBBS, and the low stress zone with an area ratio of $12.74 \%$ appears as the arc-shaped distribution. These indicate relatively weak overall stability of the ARBBS. When $q$ and $F(250 \mathrm{kN})$ act on the ARBBS (Figure 14(b)), the single hydraulic prop can reduce ARBBS span, yield the rock pressure, and increase the working resistance to improve the stress state and control 


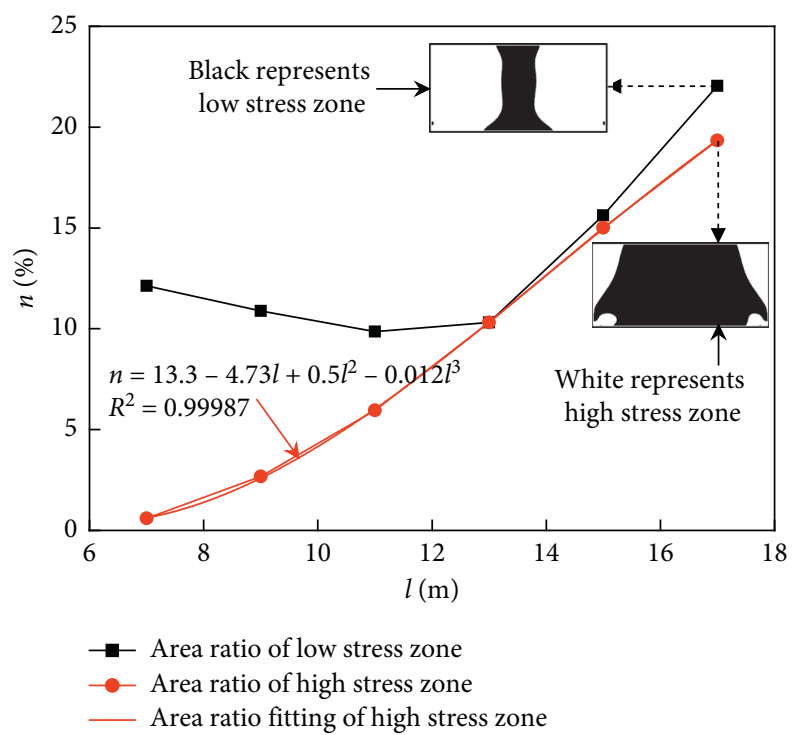

FIgURE 13: Area ratio distributions of low and high stress zones in ARBBS with different spans.

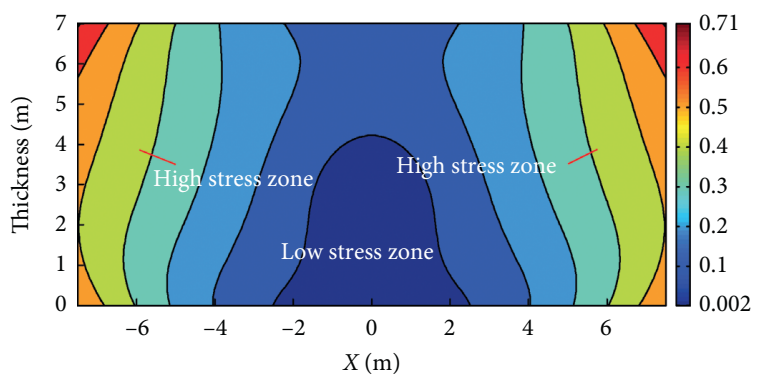

(a)

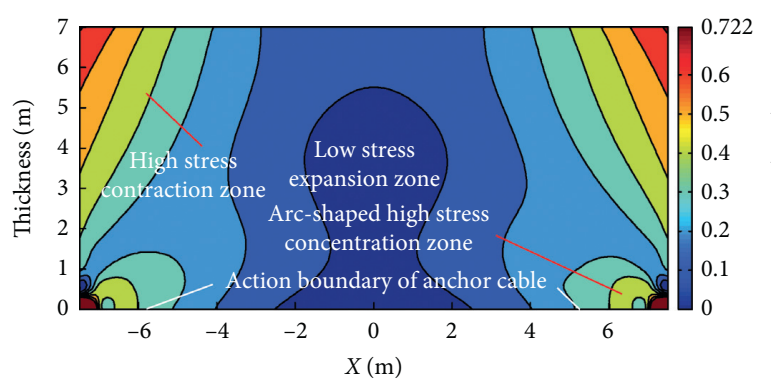

(c)

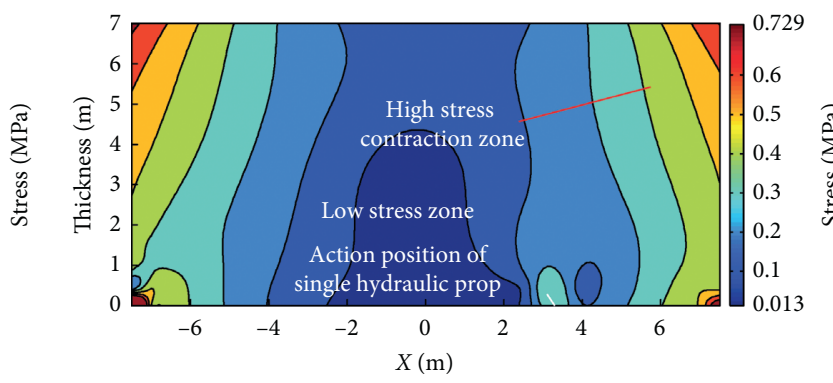

(b)

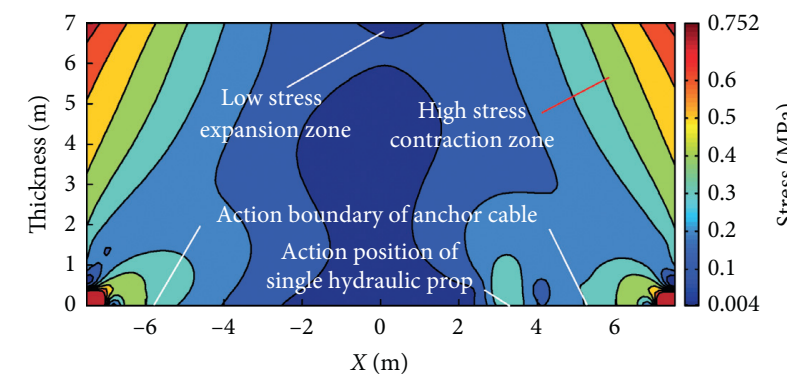

(d)

FIGURE 14: MSS distributions in ARBBS under the functions of roof load, single hydraulic prop, and anchor cables. (a) Function of $q$. (b) Functions of $q$ and $F$. (c) Functions of $q$ and $p$. (d) Functions of $q, F$, and $p$.

TABLE 3: Area ratios of low stress zone and high stress zones in ARBBS under the functions of different influencing factors.

\begin{tabular}{lccc}
\hline Function of influencing factor & Low stress zone area ratio $n_{1}(\%)$ & High stress zone area ratio $n_{2}(\%)$ & $n_{1} / n_{2}$ \\
\hline$q$ & 12.74 & 23.78 & 0.54 \\
$q, F$ & 12.27 & 20.14 & 0.61 \\
$q, p$ & 15.62 & 15.01 & 1.04 \\
$q, F, p$ & 16.84 & 14.21 & 1.19 \\
\hline
\end{tabular}

the surrounding rock deformation in the roof. However, the small-scale inclined stress concentration zone appears as arc-shaped and tends to result in the shear failure of the rock mass at the action position of the single hydraulic prop.
Therefore, it is essential to add the metal articulated top beam to effectively facilitate relatively uniform stress dispersion. It can also be seen that when $q$ and $p$ act on the ARBBS (Figure 14(c)), the high stress zone significantly 
contracts towards both sides of the ARBBS, and the low stress zone expands into the deep surrounding rock. Additionally, there is the presence of stress concentration at the corners of the ARBBS. Hence, the high-strength roof anchor bolts with the surface protecting components should be used to improve the physical and mechanical performances and stress state of the rock mass, especially in the shallow surrounding rock. When $q, F$, and $p$ act on the ARBBS (Figure $14(\mathrm{~d}))$, the low stress zone area ratio $\left(n_{1}\right)$ increases by $32.18 \%$ and the high stress zone area ratio $\left(n_{2}\right)$ decreases by $40.24 \%$ compared to the corresponding stress zone in Figure 14(a). These indicate that the single hydraulic prop of $250 \mathrm{kN}$ in working resistance and high-strength roof anchor cables, $8500 \mathrm{~mm}$ in length and $1000 \mathrm{~mm} \times 1600 \mathrm{~mm}$ in interrow spacing, can maintain the overall stability of the ARBBS.

\subsubsection{Cooperative Control Principle of Roof ARBBS and Two} Rib Anchorage Bearing Structures. According to the above analysis, it can be seen that the ARBBS cannot sufficiently control the surrounding rock deformation, since the stress concentration is relatively high at the corners of the ARBBS. However, the coal rib possesses certain load-bearing capacity. The two coal ribs interacting with the pretensioned high-strength anchor bolts and anchor cables support system can form the two stable rib anchorage bearing structures. They can efficiently support the ARBBS in bearing some roof load to maintain the integrity of the surrounding rock, thereby avoiding the rib spalling and an increase in the ARBBS span [13]. Resultantly, the roof ARBBS and two rib anchorage bearing structures cooperatively control the surrounding rock deformation and failure in the open-off cut.

Combining the production and geological conditions of the test site and field engineering practices, the maximum width $c$ of the unstable triangular block in the two coal ribs is calculated to be $1750 \mathrm{~mm}$ according to equation (4). The pretensioned high-strength rib anchor bolt, $2100 \mathrm{~mm}$ in length and $20 \mathrm{~mm}$ in diameter, is determined considering the length of its exposed part and other factors. Additionally, it should be noted that the pretensioned high-strength rib anchor cable should be applied to reinforce the goaf coal rib, thus further increasing the support strength and stiffness. Previous studies have shown that the anchor cable length in the goaf coal rib should be greater than the stress limit equilibrium zone width $x_{0}$ [42]. $x_{0}$ is given by

$$
x_{0}=\frac{M A}{2 \tan \varphi_{0}} \ln \left(\frac{k \gamma H+\left(c_{0} / \tan \varphi_{0}\right)}{\left(c_{0} / \tan \varphi_{0}\right)+\left(p_{x} / A\right)}\right) \text {. }
$$

Here, $M$ is the mining height; $A$ is the side pressure coefficient; $k$ is the stress concentration factor; $H$ is the depth of open-off cut below ground surface; $c_{0}$ is the cohesion of the interface between the coal seam and rock stratum; $p_{x}$ is the support strength to reinforce the goaf coal rib; and $\gamma$ is the average volume weight of overlying strata.

According to the field observations, measurements, and the mechanical properties of the rock mass at the test site, the following parameters are substituted into equation (16): $M=4.5 \mathrm{~m}, \quad A=0.7, \quad k=1.4, \quad H=850 \mathrm{~m}, \quad c_{0}=3.5 \mathrm{MPa}$, $\varphi_{0}=40.5^{\circ}, p_{x}=0.15 \mathrm{MPa}$, and $\gamma=25 \mathrm{kN} / \mathrm{m}^{3} . x_{0}$ is calculated to be $3800 \mathrm{~mm}$. The pretensioned high-strength rib anchor cable in the goaf coal rib, $4500 \mathrm{~mm}$ in length and $17.8 \mathrm{~mm}$ in diameter, is determined considering the length of its exposed part and other factors.

5.4. Combined Support Scheme. Based on the above analyses, the logic relation diagram of the surrounding rock deformation control around the extra-large width open-off cut is presented in Figure 15 and was applied to the newly developed area of 1128 open-off cut [43]. The 1128 open-off cut, $3.8 \mathrm{~m}$ in height and $11.5 \mathrm{~m}$ in width, was formed by excavating thrice. These were as follows: first digging the guided roadway with a width of $3.0 \mathrm{~m}$, second digging the enlarging roadway with a width of $4.0 \mathrm{~m}$ in the goaf coal rib, and third digging the other enlarging roadway with a width of $4.5 \mathrm{~m}$ in the advancing coal rib. According to the production and geological conditions of the test site, simulation results, theoretical analysis with equations (1)-(16), and field engineering practices, the final combined support scheme is shown in Figure 16.

As shown in Figure 16, the roof was supported by high-strength steel anchor bolts, $22 \mathrm{~mm}$ in diameter and $2400 \mathrm{~mm}$ in length, with a high-strength load-bearing plate and the interrow spacing to be $700 \mathrm{~mm} \times 800 \mathrm{~mm}(18$ anchor bolts per row). High-strength nineteen-strand steel anchor cables, $21.8 \mathrm{~mm}$ in diameter and $8500 \mathrm{~mm}$ in length with a tensile capability of $582 \mathrm{kN}$, were also used for supporting the roof. The interrow spacing of the anchor cables was $1000 \mathrm{~mm} \times 1600 \mathrm{~mm}$ (11 anchor cables per row). The two coal ribs were supported by highstrength steel anchor bolts, $20 \mathrm{~mm}$ in diameter and $2100 \mathrm{~mm}$ in length. The interrow spacing of the anchor bolts in the advancing coal rib was $900 \mathrm{~mm} \times 900 \mathrm{~mm}$, while that in the goaf coal rib was $850 \mathrm{~mm} \times 800 \mathrm{~mm}$. The goaf coal rib was also supported by high-strength steel anchor cables, $17.8 \mathrm{~mm}$ in diameter and $4500 \mathrm{~mm}$ in length, with the interrow spacing to be $1100 \mathrm{~mm} \times 1600 \mathrm{~mm}$. The roof anchor bolts and rib anchor bolts were connected with steel beams, $14 \mathrm{~mm}$ in diameter and $4200 \mathrm{~mm}$ in length and $12 \mathrm{~mm}$ in diameter and $3800 \mathrm{~mm}$ in length, respectively. The roof anchor cables were connected with the channel steels, $140 \mathrm{~mm}$ in height, $60 \mathrm{~mm}$ in width, and $8 \mathrm{~mm}$ in thickness. The anchor bolts in the roof and rib corners were installed at $45^{\circ}$ incline and $75^{\circ}$ incline, respectively, and the anchor cables in the roof corners were installed at $15^{\circ}$ incline. The sizes of the high-strength diamond steel mesh, $6 \mathrm{~mm}$ in diameter, for the roof and rib surface control were $4000 \mathrm{~mm} \times 4000 \mathrm{~mm}$ and $3800 \mathrm{~mm} \times 3800 \mathrm{~mm}$, respectively. The anchor bolts and anchor cables in the roof were installed with a pretension of $90 \mathrm{kN}$ and $240 \mathrm{kN}$, respectively. The anchor bolts and anchor cables in the ribs were installed with a pretension of $70 \mathrm{kN}$ and $170 \mathrm{kN}$, respectively. In addition, the DW-250/100 single hydraulic prop of $250 \mathrm{kN}$ in working resistance with a DJB- 


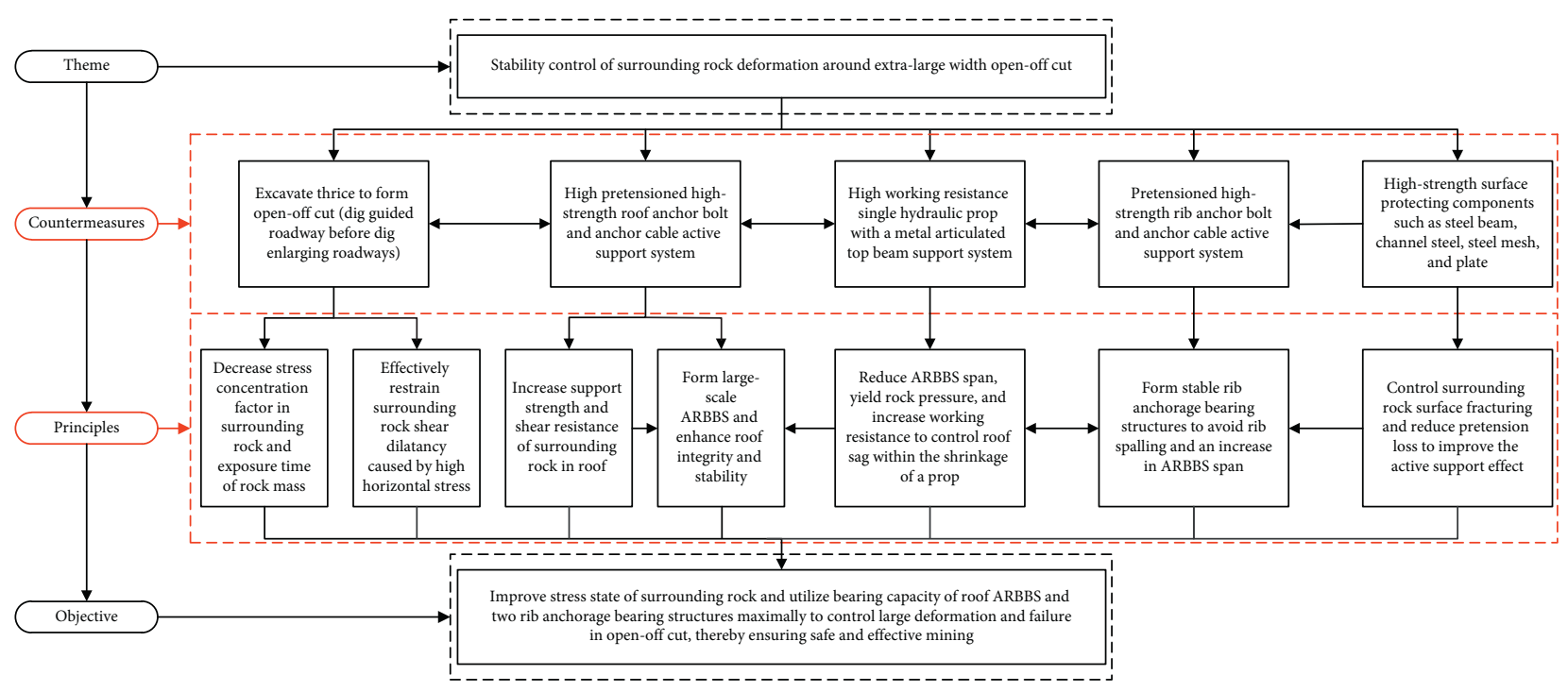

FIGURE 15: Logic relation diagram of surrounding rock deformation control around extra-large width open-off cut.

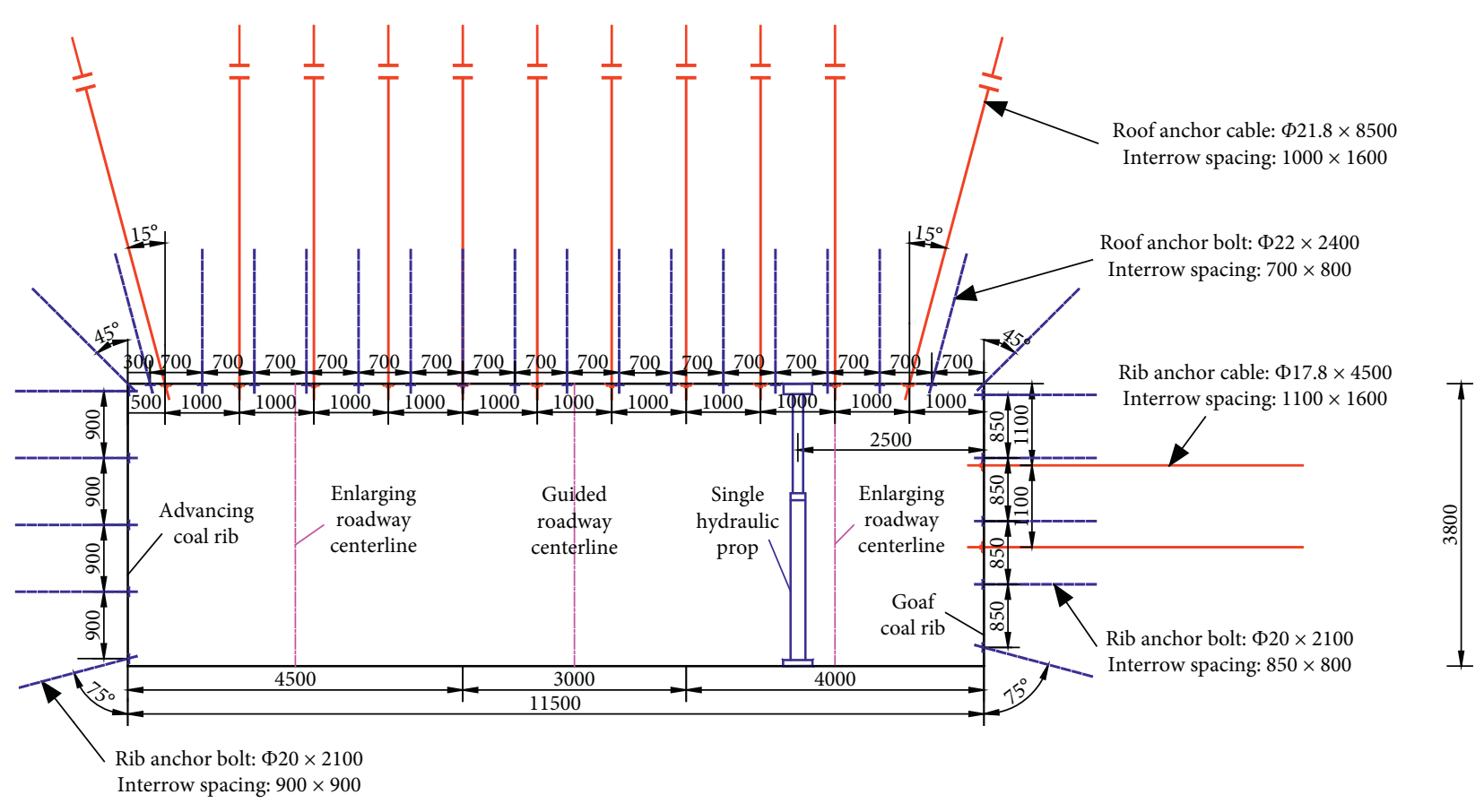

(a)

Figure 16: Continued. 


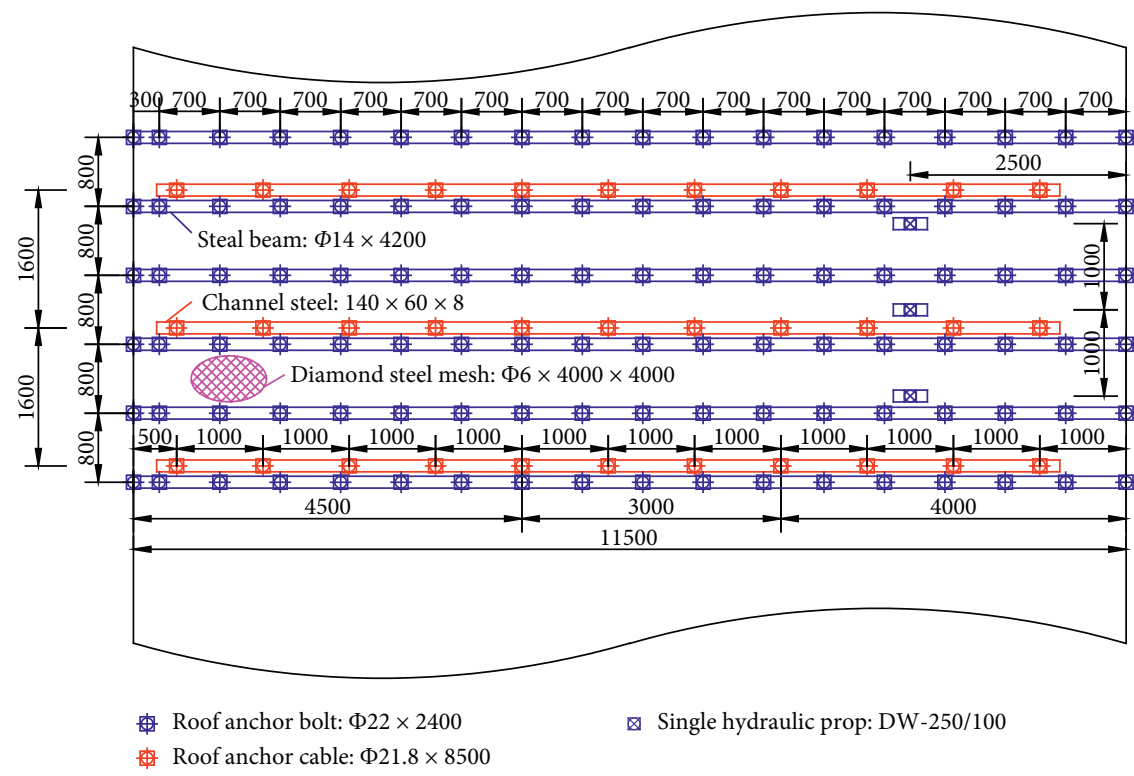

(b)

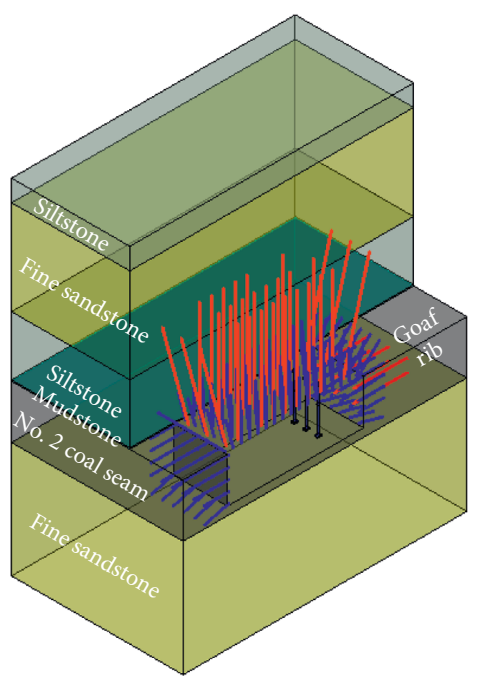

(c)

Figure 16: Combined support scheme in the 1128 open-off cut (unit: mm). (a) Supported section. (b) Roof support. (c) Three-dimensional support.

1000 metal articulated top beam was set up to reinforce the roof strata. The distance between the single hydraulic prop and goaf coal wall was $2500 \mathrm{~mm}$ and the rows were spaced at $1000 \mathrm{~mm}$.

5.5. Support Effect. The surrounding rock surface convergences of the 1128 open-off cut at the monitoring station were monitored by adopting the cross-point method to test the support effect of the combined support scheme. The monitoring results are shown in Figure 17. It was found that the deformation rapidly increased within the first 15 days, slowly increased in the next 15-42 days, and stabilized in the next 42-60 days, and the convergence rate was found to be less than $1.5 \mathrm{~mm} / \mathrm{d}$. The final roof sag, floor heave, and ribto-rib convergences were found to be $174 \mathrm{~mm}, 121 \mathrm{~mm}$, and $241 \mathrm{~mm}$, respectively, and the deformations were in the allowable range. Meanwhile, the obvious bed separation failed to occur within the anchorage area of the roof, indicating a relatively stable roof with no fractures. The phenomena of the pullout and breakage of the anchor bolts and anchor cables, bending damage of the single hydraulic prop, roof fall, and rib spalling failed to take place. The final cross-sectional area of the open-off cut was found to be $90.3 \%$ of the original cross-sectional area in the field. This met the requirement for the fast development of the open-off cut and the quick and timely installations of backfill mining equipment.

Field applications indicate that the stress state of the surrounding rock under the functions of high pretensioned highstrength roof anchor bolts and anchor cables, high working resistance single hydraulic prop, and two rib anchorage bearing structures is improved. The support strength significantly increases. The load-bearing capacity of the roof ARBBS and two

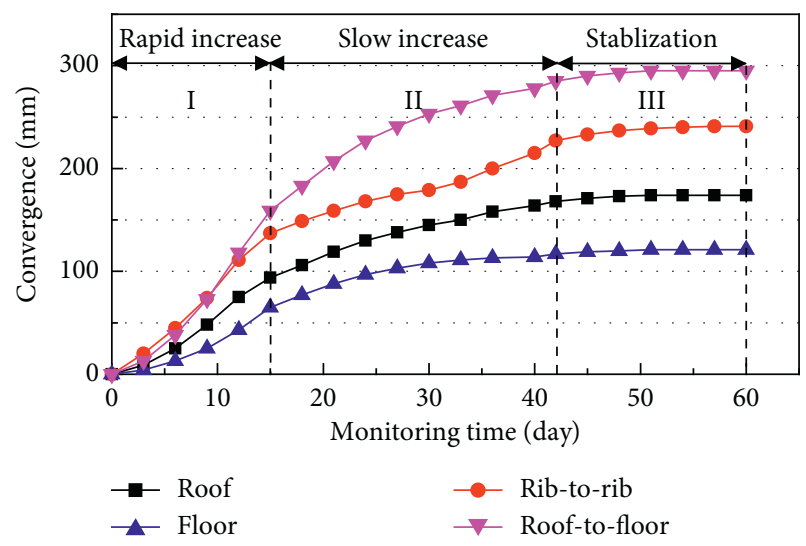

FIGURE 17: Monitored convergences in the 1128 open-off cut.

rib anchorage bearing structures is utilized maximally, thereby successfully controlling the large deformation and failure of the surrounding rock and eliminating the risk of the dynamic disasters. This validates the ARBBS model results and contributes to the safe and effective mining operations in underground coal seam mining.

\section{Conclusions}

In order to solve the problem of surrounding rock control of an extra-large width open-off cut in backfill mining, the formation mechanism and bearing characteristics of roof anchorage rock beam bearing structure (ARBBS) of extralarge width open-off cut were researched by means of field investigation, numerical simulation, theoretical analysis, and engineering practice. The main conclusions are summarized as follows: 
(1) The effective prestressed field in the extra-large width open-off cut roof was found to be nearly rectangular along the open-off cut cross section. The effective anchorage area of the roof could fulfill the assumption of a beam and form the approximately $7 \mathrm{~m}$-thick ARBBS. The roof load, single hydraulic prop, and anchor cable were found to be the influencing factors that significantly affected the ARBBS stability. The calculation equation of the maximum shear stress (MSS) in the ARBBS, under the functions of these influencing factors, was obtained. The area ratio distribution of high stress zone was found to exponentially increase with decreasing ARBBS thickness. The area ratio of high stress zone was fitted by the cubic function and increased rapidly with increasing ARBBS span. However, the high resistance single hydraulic prop reducing-span and high pretensioned high-strength roof anchor bolts and anchor cables supports effectively improved the MSS state in the ARBBS. This increased the area ratio of low stress zone by $32.18 \%$ and decreased the area ratio of high stress zone by $40.24 \%$ compared to the corresponding stress zone under unsupported condition. Additionally, the roof ARBBS and two rib anchorage bearing structures cooperatively bore the roof load resulting in a better deformation-controlling effect. Finally, a combined support scheme was implemented in the $11.5 \mathrm{~m}$-wide 1128 open-off cut. Field applications validated the ARBBS model and its findings.

(2) For surrounding rock control of roadways with flat roof, the traditional composite beams structure is formed by superposition and combination of some thin rock strata. According to the simple bending theory of beams, the equation of traditional composite beams structure model is derived. The equation may not comprehensively research the stress distribution pattern, stress size, and other stress variation laws of whole beam. However, the ARBBS is a whole anchorage bearing structure, which is formed under the function of effective prestressed field produced by bolts and anchor cables support. According to the elastic mechanics theory, the calculation equation of the MSS in ARBBS model is derived. The equation considers the influence of effective anchorage thickness, span, roof load, single hydraulic prop support force, anchor cable support strength, and other factors on the stability of the ARBBS. The variation laws (such as stress distribution pattern, stress peak value, and high and low stress area) of the MSS in whole beam under the functions of different factors are analyzed in detail. Consequently, the bearing characteristics of the ARBBS are revealed, so as to optimize the support scheme of roadway and realize the purpose of giving full play to whole bearing capacity of roadway surrounding rock. Evidently, the research of the ARBBS model considers more factors and is more detailed, comprehensive, scientific, and reasonable, which is in line with engineering reality.

(3) Of course, due to the extremely complex mining geological conditions, the traditional composite beams model may not comprehensively research, and the ARBBS model may not fully reflect. However, the research of the ARBBS model reveals the mechanism of controlling the deformation and failure of rock mass around extra-large width openoff cut. The research considers more practical factors and greatly makes up for defects and deficiencies of traditional composite beams model conclusion. There is further advance on the cognitive level of theory and practice.

\section{Data Availability}

The data used to support the findings of this study are available from the corresponding author upon request.

\section{Conflicts of Interest}

The authors declare that there are no conflicts of interest regarding the publication of this paper.

\section{Acknowledgments}

The authors would like to acknowledge Editage (http://www. editage.com) for English language editing. This work was supported by the National Natural Science Foundation of China (no. 52074296 and no. 52004286), the Yue Qi Young Scholar Project, China University of Mining \& Technology, Beijing (no. 800015Z1104), the China Postdoctoral Science Foundation (no. 2020T130701 and no. 2019M650895), the Fundamental Research Funds for the Central Universities (no. 2020YJSNY06).

\section{References}

[1] X. Zhao, X. Yue, C. Tang, and W. Zhu, "Study on destructional law of open-off cut surrounding rockmass," Journal of Liaoning Technical University, vol. 24, no. 3, pp. 357-359, 2005.

[2] H. Kang, J. Lin, and M. Fan, "Investigation on support pattern of a coal mine roadway within soft rocks - a case study," International Journal of Coal Geology, vol. 140, pp. 31-40, 2015.

[3] Q. Huang and F. Gao, "Large section open-off cut supporting technology of fully mechanized caving mining for carboniferous extra-thick coal seam," Advanced Materials Research, vol. 734-737, pp. 566-569, 2013.

[4] W. Liu, J. Xu, W. Zhu, and S. Wang, "A novel short-wall caving zone backfilling technique for controlling mining subsidence," Energy Science \& Engineering, vol. 7, no. 5, pp. 2124-2137, 2019.

[5] H. Yan, J. Zhang, S. Zhang, and N. Zhou, "Physical modeling of the controlled shaft deformation law during the solid backfill mining of ultra-close coal seams," Bulletin of Engineering Geology and the Environment, vol. 78, no. 5, pp. 3741-3754, 2019.

[6] M. Li, J. Zhang, P. Huang, and R. Gao, "Mass ratio design based on compaction properties of backfill materials," Journal 
of Central South University, vol. 23, no. 10, pp. 2669-2675, 2016.

[7] X. Miao, "Progress of fully mechanized mining with solid backfilling technology," Journal of China Coal Society, vol. 37, no. 8, pp. 1247-1255, 2012.

[8] J. Zhang, Q. Sun, N. Zhou, H. Jiang, D. Germain, and S. Abro, "Research and application of roadway backfill coal mining technology in western coal mining area," Arabian Journal of Geosciences, vol. 9, no. 10, p. 10, 2016.

[9] Q. Ding and Y. Zhou, "Tunneling method and support installation in large span open-off cut of solid backfill mining," Journal of China Coal Society, vol. 40, no. 6, pp. 1333-1338, 2015.

[10] C. Li, Y. Cao, Z. Cheng, J. Xu, and L. Chen, "Roof collapse laws and reducing-span support technology in long-span roadway," Journal of Mining \& Safety Engineering, vol. 32, no. 6, pp. 978-983, 2015.

[11] S. Gu, B. Jiang, G. Wang, H. Dai, and M. Zhang, "Occurrence mechanism of roof-fall accidents in large-section coal seam roadways and related support design for Bayangaole Coal Mine," Advances in Civil Engineering, vol. 2018, Article ID 6831731, 17 pages, 2018.

[12] H. Jia, N. Ma, X. Zhao, and S. Zhang, "Research on the law of instability and caving for large-span cut-hole roof with thin bedrock in depth," Journal of Mining \& Safety Engineering, vol. 31, no. 5, pp. 702-708, 2014.

[13] F. He, L. Xu, H. Wu, and T. Li, "Deviatoric stress transfer and stability of surrounding rock in large-section open-off cut roof," Chinese Journal of Geotechnical Engineering, vol. 36, no. 6, pp. 1122-1128, 2014.

[14] B. Meng, H. Jing, K. Chen, and H. Su, "Failure mechanism and stability control of a large section of very soft roadway surrounding rock shear slip," International Journal of Mining Science and Technology, vol. 23, no. 1, pp. 127-134, 2013.

[15] S. Xie, H. Pan, J. Zeng et al., "A case study on control technology of surrounding rock of a large section chamber under a 1200-m deep goaf in Xingdong coal mine, China," Engineering Failure Analysis, vol. 104, pp. 112-125, 2019.

[16] S. Zhang, D. Zhang, H. Wang, and S. Liang, "Discrete element simulation of the control technology of large section roadway along a fault to drivage under strong mining," Journal of Geophysics and Engineering, vol. 15, no. 6, pp. 2642-2657, 2018.

[17] W. Yu and S. Du, "Numerical simulation on supporting of large section open-off cut and its stability," Electronic Journal of Geotechnical Engineering, vol. 19, pp. 1619-1634, 2014.

[18] M. Qian, P. Shi, and J. Xu, Mining Pressure and Strata Control, China University of Mining and Technology Press, Xuzhou, China, 2010.

[19] C. C. Li, "Rock support design based on the concept of pressure arch," International Journal of Rock Mechanics and Mining Sciences, vol. 43, no. 7, pp. 1083-1090, 2006.

[20] S. S. Peng and D. H. Y. Tang, "Roof bolting in underground mining: a state-of-the-art review," International Journal of Mining Engineering, vol. 2, no. 1, pp. 1-42, 1984.

[21] U. M. R. Karanam and S. K. Dasyapu, "Experimental and numerical investigations of stresses in a fully grouted rock bolts," Geotechnical and Geological Engineering, vol. 23, no. 3, pp. 297-308, 2005.

[22] H. Kang, J. Li, J. Yang, and F. Gao, "Investigation on the influence of abutment pressure on the stability of rock bolt reinforced roof strata through physical and numerical modeling," Rock Mechanics and Rock Engineering, vol. 50, no. 2, pp. 387-401, 2017.
[23] S. Wan, Research on Collapse Mechanism and Surrounding Rock Control of Large-Span Roadway in Deep, China University of Mining and Technology, Xuzhou, China, 2011.

[24] S. Xie, M. Gao, D. Chen et al., "Stability influence factors analysis and construction of a deep beam anchorage structure in roadway roof," International Journal of Mining Science and Technology, vol. 28, no. 3, pp. 445-451, 2018.

[25] L. Jiang, P. Kong, J. Shu, and K. Fan, "Numerical analysis of support designs based on a case study of a longwall entry," Rock Mechanics and Rock Engineering, vol. 52, pp. 3373-3384, 2019.

[26] Q. Jiang, X. Feng, and T. Xiang, "Discussion on method for calculating general safety factor of underground caverns based on strength reduction theory," Rock and Soil Mechanics, vol. 30, no. 8, pp. 2483-2488, 2009.

[27] K. Zhang, G. Zhang, R. Hou, Y. Wu, and H. Zhou, "Stress evolution in roadway rock bolts during mining in a fully mechanized longwall face, and an evaluation of rock bolt support design," Rock Mechanics and Rock Engineering, vol. 48, no. 1, pp. 333-344, 2015.

[28] W. Wu, J. Bai, X. Wang, S. Yan, and S. Wu, "Numerical study of failure mechanisms and control techniques for a gob-side yield pillar in the Sijiazhuang coal mine, China," Rock Mechanics and Rock Engineering, vol. 52, no. 4, pp. 1231-1245, 2019.

[29] G. Zhang, F. He, and L. Jiang, "Analytical analysis and field observation of break line in the main roof over the goaf edge of longwall coal mines," Mathematical Problems in Engineering, vol. 2016, Article ID 4720867, 11 pages, 2016.

[30] Z. Zhang, J. Bai, W. Wang, Y. Chen, X. Yu, and H. Wu, "Mechanical analysis of roof separation within and outside anchorage zone above backfill area of gob-side entry retaining and its engineering application," Journal of Mining \& Safety Engineering, vol. 35, no. 5, pp. 893-901, 2018.

[31] W. Yu, Q. Gao, and C. Zhu, "Study of strength theory and application of overlap arch bearing body for deep soft surrounding rock," Chinese Journal of Rock Mechanics and Engineering, vol. 29, no. 10, pp. 2134-2142, 2010.

[32] Y. Zeng, Y. Wu, X. Lai, and C. Wei, "Analysis of roof caving instability mechanism of large-section roadway under complex conditions," Journal of Mining \& Safety Engineering, vol. 26, no. 4, pp. 423-427, 2009.

[33] S. Xie, M. Gao, D. Chen, H. Su, and S. Lan, "Deep beam support structure construction of roadway roof with monorail crane and its application," Journal of China Coal Society, vol. 42, no. 6, pp. 1420-1428, 2017.

[34] Y. Yu and L. Ma, "Application of roadway backfill mining in water-conservation coal mining: a case study in Northern Shaanxi, China," Sustainability, vol. 11, no. 13, p. 22, 2019.

[35] W. Pan, X. Nie, and X. Li, "Effect of premining on hard roof distress behavior: a case study," Rock Mechanics and Rock Engineering, vol. 52, no. 6, pp. 1871-1885, 2019.

[36] M. Deng, F. Ma, B. Li, and X. Liang, "Analysis on shear capacity of SRC deep beams based on modified strut-and-tie model," Engineering Mechanics, vol. 34, no. 12, pp. 95-103, 2017.

[37] Z. Xu, A Concise Course in Elasticity, Higher Education Press, Beijing, China, 3rd edition, 2002.

[38] C. Zhan and Y. Liu, "Analytical solutions for beams with fixed ends," Chinese Journal of Applied Mechanics, vol. 33, no. 2, pp. 201-207, 2016.

[39] W. Yu, G. Wu, B. An, and P. Wang, "Experimental study on the brittle-ductile response of a heterogeneous soft coal rock 
mass under multifactor coupling," Geofluids, vol. 2019, p. 15, Article ID 5316149, 2019.

[40] W. Yu and F. Liu, "Stability of close chambers surrounding rock in deep and comprehensive control technology," $A d-$ vances in Civil Engineering, vol. 2018, Article ID 6275941, 18 pages, 2018.

[41] W. Gao, L. Shi, J. Han, and P. Zhai, "Dynamic monitoring of water in a working face floor using $2 \mathrm{D}$ electrical resistivity tomography (ERT)," Mine Water and the Environment, vol. 37, no. 3, pp. 423-430, 2018.

[42] C. Hou and N. Ma, "Stress in in-seam roadway sides and limit equilibrium zone," Journal of China Coal Society, no. 4, pp. 21-29, 1989.

[43] G. Zhang, F. He, Y. Lai, and H. Jia, "Ground stability of underground gateroad with $1 \mathrm{~km}$ burial depth: a case study from Xingdong coal mine, China," Journal of Central South University, vol. 25, no. 6, pp. 1386-1398, 2018. 